\title{
LA HISTORIA CONTEMPORANEA EN ESPAÑA: TENDENCIAS RECIENTES
}

\author{
por \\ ELENA HERNÁNDEZ SANDOICA \\ Universidad Complutense de Madrid
}

RESUMEN: Este ensayo pretende revisar la historiografia contemporanetsta española a lo largo de los últimos veinticinco años. En lugar de insistir en la natural acumulación temática y bibliográfica, propia del crecimiento de la disciplina, la autora propone considerar ante todo las transformaciones metodológicas y las inspiraciones e influencias exteriores - los préstamos-, a la hora de trazar el balance de este cuarto de siglo. Y entiende que sólo asi es posible detectar las carencias y valorar los logros actuales.

Palabras Clave. Metodología, Teoría, Historla, España.

ABSTRACT: This essay attempts to review Spanish historiography of contemporary history over the course of the last twenty-five years. Instead of insisting on the natural thematic and bibliographical accumulation that accompanies the growth of the discipline, the author proposes above all to consider the methodological transformations and the outside inspirations and influences the borrowings- and at the same time to show the results of this quarter century. It should be understood that only in this way is it possible to detect current shortocomings and to evaluate current achievements.

KEY WORDS: Methodology, theory, historiography, Spain.

1. Hace ya casi veinticinco años que José María Jover prologó la edición de diversos trabajos de discípulos suyos con un largo estudio bibliográfico, uno de los muy raros balances de historiografía de principios de los años setenta, que logró una acogida extraordinaria entre la profesión '. Se trataba

1 Jover Zamora, J. M., había editado antes, en inglés (1961): «Panorama of Current Spanish Historiography): Cahiers d'Histoire Mondiale VI/3: 1023-1038. El texto fundamental es sin 
de «El siglo XIX en la historiografía española contemporánea (1929-1972)», un texto minucioso que veŕa la luz en 1974 a manera de prólogo o introducción.

Desde esa fecha hasta casi hoy mismo se ha citado con profusión aquel trabajo, un balance cuidado e informado, ponderado en sus términos y en su elaboración. Tanto ha sido empleado su diagnóstico como argumento sólido de autoridad que podría seguirse desde entonces sin interrupción el hilo de las referencias realizadas a ese artículo extenso - un libro por sí solo-, cuya vigencia alaban ciertos profesionales todavía, puestos a calibrar qué es lo que se hace ahora, en tiempos recientísimos, en el terreno de la Contemporánea en expansion.

Sucede sin embargo que al situarlo en ese plano horizontal y ucrónico ocultan precisamente lo que, a mi parecer, el texto es más que nada. En primer lugar, se trata de una clave de bóveda en la confirmación del cambio que se iba produciendo en la subdisciplina al iniciarse los años 70: la Historia toda estaba en mutación y, dentro de ella, la Contemporánea iba encontrando un especial perfil. "El siglo XIX en la historiografía" resulta, así, una especie de puesta de largo, un acta autorizada de legitimación para dejar constancia de cuál estaba siendo la transformación de objetos de estudio que apuntaba en España, con toda claridad, en el último quinquenio del franquismo. Y para inaugurar, a aquella hora misma, su celebración.

Pero también, y no en menor medida, entiendo que es aquel un texto de valor normativo, orientador de la investigación -quizá sin pretenderlo-; una especie de código informal, de guía o de plantilla que iba a mostrarse activo en cuanto a la manera de organizarse a partir de ahí la propia disciplina; un mecanismo práctico de ordenación y de regulación de la materia empírica, en el proceso de densificación y multiplicación que por entonces empezó a devolver su carácter formalmente científico, en España, al conjunto de la profesión.

Se ocupaba Jover, como se ha recordado en más de una ocasión, del incipiente auge entre nosotros de las investigaciones históricas dedicadas a la España del siglo pasado. Habían ido aliviándose la fantasmagoría anticonstitucional y el visceral rechazo del liberalismo que eran consustanciales al franquismo, y -ya desde la década anterior-estaban siendo abandonados los prejuicios ideológicos que habían arrumbado, a veces con violencia, recuerdos de una España que fuera liberal. Secuestrado y mermado por esa anomalía, nuestro siglo xIx había devenido opaco para los historiadores, convertido en objeto científico olvidado e inexistente. Era ésta una carencia extremamente grave, paradoja además, puesto que el propio término liberal, expandido por Europa con las revoluciones del periodo, había nacido aquí, en las Cortes de Cádiz.

embargo el de 1974: "El siglo XIX en la historiografia española contemporánea (1939-1972)», al frente del tibro colectivo El siglo XIX en España: doce estudios, Barcelona, Planeta: 9-152. Fruto de un importante ciclo de conferencias en la Fundación Juan March fue, después, otro mucho más breve (1976): “Corrientes historiográficas en la España contemporánea», en CARRERAS, J. J., y otros, Once ensayos sobre la historia, Madrid, Rioduero: 215-247.

Hixpania, LVHIUI, núm. 198 (1998) 65-95 
Pero esa situación anómala e injusta parecía cambiar. En los estudios nuevos -seguía Jover diciendo- gobernaba la idea de que esa historia, hasta ahí secuestrada, había que hacerla, y, para hacerla, se acudía a unas fuentes que, en su mayoría, resultaban ser nuevas. Es decir, documentos distintos a los tradicionales en historiografía, complementarios de los usuales por lo general, y más variados, aunque siempre escritos. Documentos que, empleados con cautela y rigor, iban reconstruyendo una idea del pasado menos sujeta a estereotipos ideológicos, menos aprisionada en los engaños y en las elusiones de una parte importante de la realidad.

De un interés creciente por el XJX entre los estudiosos españoles de la historiografía se derivaba así, casi de seguido, el contemporaneísmo como especialización, un ensayo de parcelación académica que había de ser llevado de inmediato a los planes de estudio, cuya renovación comenzaba igualmente en aquellos momentos. Y ese despunte de una subdisciplina joven, que tanto prometía, nacía alimentado - siempre según Jover - por el sustrato hondo, cultural y político, abonado por una antigua tradición española: la que fue inaugurada a principios del siglo por el liberalismo doceañista y quedó suspendida, mediante la violencia, varias veces después.

Así pues, con ese afloramiento de ideas y creencias liberales $-\mathrm{y}$ por eso radical y legítimamente españolas también-, se reabría la posibilidad de inaugurar un objeto científico más actual, más acorde con los cambios sociales e ideológicos que andaban imprimiendo un nuevo giro a la situación del país. Nacía de este modo un objeto historiográfico vivo y acomodado a las exigencias del momento, pero también forjado en el magma profundo de ideales y esperanzas antiguos, directamente emparentado con el reencuentro de los españoles con el liberalismo. Y ello se producía -citando textualmente a mi maestro Jover- sin recurrir obligatoriamente a patrones extraños ni a influencias foráneas, ajenas a lo propio (a lo nacional), sino - por el contrario- emergiendo espontáneas las ideas y principios desde el mismo «interior de la historiografía peninsular».

Eso decía en suma, más o menos Jover, buscando en el pasado, y en los grandes autores y supuestos de la historiografía liberal española del siglo XIX (en su versión «moderada», desde luego, también), los argumentos básicos y las líneas maestras de su interpretación. Sobre aquel basamento establecido por la historiografía derivada del nacionalismo decimonónico español nacía así una propuesta de reconstrucción de amplio espectro y alcance, preparada del todo para buscar respaldo entre los estudiosos y encontrar fortuna. Y comenzaba a levantarse un pórtico interpretativo que iba a quedar centrado, prioritariamente, en los recursos propios del historicismo y de la historia sociocultural, los cuales eran rescatados, ante todo, a través de la novela del realismo español. Una interpretación, en definitiva, que sería no sólo desplegada, desde entonces acá, por el mismo José María Jover en muchas de sus obras, sino que tambien ha venido a servir como telón de fondo, como marco flexible si se quiere, para investigaciones de autores muy distintos, directamente vinculados o no a su magisterio. (Si bien la mayoría de estos últimos le superponen a su vez otros enfoques o 
influencias mixtas ${ }^{2}$; muchas de ellas, hasta hace bien poco, venidas del marxismo).

Nada apuntaba aquel texto esencial, a pesar de sus características formales -con un recuento bibliográfico y una identificación de novedades casi exhaustivos-, hacia problemas técnicos o posibilidades de otro tipo en la escritura de la historia, en esa nueva era que amanecía al fin. Sólo hacía alusión, aunque de vez en cuando, a la posibilidad de que hubieran llegado a nuestro suelo inspiraciones de teoría y método distintas a las predominantes hasta entonces. A pesar de la extensión y densidad de aquel escrito, pues, cuidado y medidísimo, nada en su seno permitía al lector averiguar de modo sistemático dónde se hallaban los virajes internos que impulsaban acaso, desde dentro también de la propia disciplina, como consecuencia quizá de una expansión de origen interior, el evidente salto acometido por la investigación ${ }^{3}$.

Se esbozaba el asunto, como puede comprobarse fácilmente, al citarse al catalán Vicens - cita obligada, transcurrida una década larga de su llorada muerte en Cataluña-, trayendo a colación su encuentro con Annales desde 1950. (Después llegaría a nuestra historiografía Braudel, junto con la directa influencia de Vilar). También se rozaba la cuestión al hablar de la entrada de Tuñón en el mercado científico español, cuando empezaba a ser un hecho la irrupción exitosa de sus ágiles libros a principios de los años 70 (estudiantes de entonces y licenciados jóvenes, y no sólo en Historia, considero que fuimos sus lectores), en un fenómeno de proyección social que en España no era acostumbrado ${ }^{4}$. En cualquier caso, la alusión a las "nuevas fuentes" y a los

2 Cirujano, P., Elorriaga, T., y Pérez Garzón, J. S., (1985): Historiografia y nacionalismo español (1834-1868), Madrid, CSIC. Esperanza Yllán, Gonzalo Pasamar e Ignacio Peiró son sin duda deudores -antes o después- de esa «ruptura» joveriana (aunque los dos últimos autores deben los fundamentos historiográficos de su orjentación a Juan José Carreras, él mismo una excepción, por mucho tiempo, en asuntos de historia de la historiografia).

Algunas intuiciones de Jover para la era isabelina se desarrollan, desde otra perspectiva, en la tesis doctoral de Rivíre Gómez, A., (1992): Historia, historiadores e historiografia en la Facultad de Letras de la Universidad de Madrid (1843-1868), Madrid, UCM. Convergen con esa panorámica ciertos intentos de historia intelectual, aislados o no, propios del análisis de los años 80. Por ejemplo MAINER, J. C., (1981): «De historiografia literaria española: el fundamento liberal», en VV. AA. Homenaje a Manuel Tuñón de Lara. Estudios de Historia de España, Madrid, UIMP, vol.II: 439-472.

3 De fundamentos teóricos para las inspiraciones nuevas dieron cuenta, entre otros, Clavero y Martínez Shaw. Del primero (1979): "Para un concepto de revolución burguesa», en CLAVERo, B., y otros, Estudios sobre la revolución burguesa en España, Madrid, Siglo XXI: 35-54; MARTiNEZ SHAW, C., (1980): «Sobre el feudalismo tardio en España: algunas acotaciones a Bartolomé Clavero», En Teoria 4: 163-186, y de nuevo Clavero (1980): "Sobre la idea de revolución burguesa: algunas puntualizaciones a Martínez Shaw», Zona Abierta 26: 123-134. Aunque FonTANA, J., intervino también en la polémica, afecta más a lo que se discute aquí su articulo (1991): «La historiografia española del siglo XIX: un siglo de renovación entre dos rupturas», en CASTILLO, S., coord. La historia social en España..., Madrid, Siglo XXI: 325-335.

4 Tuñón era en España casi invisible aún, salvo para unos pocos historiadores, economistas y sociólogos jóvenes - diversa su filiación y formación, aunque todos abiertos a la «historia social», cada año desde Madrid a Pau, atraidos por una especie de «música nueva». (La metáfora, referida

Hispania, LVIII/1, num. 198 (1998) $65-95$ 
«nuevos métodos», cosa relativamente frecuente a lo largo del extenso capítulo-marco escrito por Jover, podía aparecer como inquietante y vaga: nunca llegaba a definirse del todo cuáles estaban siendo su específica naturaleza y entidad.

Por mi parte, considero que intentar — casi un cuarto de siglo despuésun viaje de reconocimiento por los desarrollos recientes del contemporaneísmo español, un recorrido que no sea meramente enunciativo y tangencial, pide volver a aquel mismo momento inaugural. Por eso me he detenido tanto en el arranque. Aunque sé que partiendo desde ahí no será fácil, tratándose de un corte largo y de un bloque poliédrico - pido disculpas desde ahora ya-, hacer las diferenciaciones necesarias a propósito de la regionalización (acentuada desde aquellas fechas) que existe en la historiografía española, ni me será posible dar cabida justa a rasgos específicos de particularidad.

La vuelta a aquel momento es obligada, a mi modo de ver, si a medio o largo plazo se pretende contribuir a deshinchar imágenes convexas, a disipar estereotipos viejos o disfunciones del propio gremio de los historiadores al que van dirigidos, en principio, los análisis y la crítica interna de la producción ${ }^{5}$. Pero antes, es conveniente decidir donde fijar el punto de mira, cuál puede resultar el enfoque mejor.

Por mi parte, propongo situarlo en un espacio de signo transversal, un tanto incómodo posiblemente, puesto que en él no suele repararse mucho. Me gustaría hacerlo depender de la cuestión, a mi juicio nodal, de métodos y metodologías (forzoso es el plural). Situarlo, así pues, en la materialización de las diversas instrumentaciones de referencia teórica - aunque sea difusa-, y en las implicaciones técnicas que hay siempre subyacentes a la transformación de cualquier disciplina.

al método, es de Aróstegul, Julio, (1993): «Manuel Tữón de Lara y la construcción de una ciencia historiográficas, en Granja, J.L. de la y ReIo TAPIA, A., eds. Manuel Tǘón de Lara. El compromiso del historiador. Su vida y su obra, UPV, Servicio Editorial: 143-196). Textos fundamentales de Tữón de Lara, en esa dirección de movilización constante de estudiosos e investigadores son (1973): «Problemas actuales de la historiografia española»: Sistena 1: 31-50; (1974): «¿Una escuela histórica española?»: Cuadernos para el Diálogo XLII (extraordinario); (1975): "¿Qué historia? Algunas cuestiones de historiología): Sistena 9: 5-26.

A la espera de la edición de las actas del curso Manuel Tuñón de Lara y la renovación de la historiografia contenporánea (El Escorial, agosto de 1997), marca un hito todavía el texto (1980): Historiografía española contemporánea. X Coloquio de Pau. Balance y resunen, Madrid, Siglo XXI (edición de J. L. García Delgado). El balance historiográfico de los años 80 y principios de los 90 (Cuenca, UIMP, 1993) no ha visto la luz. Sólo conozco la edición, por separado, de los trabajos de Garcia-SanZ, A., y MiKelarena F., ("Demografia histórica, siglos XIX y XX): Historia Contempóranea 12, 1995: 309-337), Pérez Ledesma, M., ( «Una jealtad de otros siglos. En torno a las interpretaciones del carlismo»: Historia Social 24, 1996: 133-149) y SuÁrez CorTina, M., «La Restauración (1875-1900) y el fin del imperio colonial. Un balance historiográfico", en SUÁREZ CoRTINA, M., ed. (1997): La Restauración, entre el liberalisno y la democracia, Madrid, Alianza: 31-107.

5 A pesar de que es ésa su explícita intención, puede incitar también a reflexiones divergentes JULı̇̇, S., en un texto reciente (1996): "Anomalía, dolor y fracaso de España»: Claves de razón práctica, núm. 66: 10-21. 
Cuestiones que, en resumidas cuentas, se hallan en el fondo de toda importación de "novedades» científicas desde una comunidad científica hasta otra que le sea sensible y permeable, independientemente de cuál vaya a ser la forma que adopte ese traslado o transferencia, cuáles también sus cauces principales y su percepción. (Es decir, bien se trate en principio de una traslación colateral, desde una disciplina colindante a otra, y en el mismo contexto nacional. O bien - de modo más frecuente quizá, o al menos así era hasta hace muy poco- entre diversos ámbitos de la misma disciplina en contextos lingǘísticos y culturales que, a su vez, pueden ser similares o no; y, especialmente, por atracción y mímesis de alguna de sus corrientes principales y escuelas más dinámicas, a través de los conductos usuales de difusión y contacto científico a escala supranacional).

En nuestro caso particular, la historiografía, este proceso se ha manifestado usualmente a través de la elección de «nuevos objetos» (lo que la mayoría llama, vagamente, nuevos temas), que siempre pasan a ser considerados viables y oportunos a través de la puesta en valor y legitimación de lo que se denominan «nuevas fuentes».

Pero quizá convenga añadir algo más todavía. Y es que aquella importación circunstancial de metodologías que nutre formalmente la novedad científica (o el traslado e irrupción de instrumentaciones diferentes de las convencionales en una disciplina hasta un momento dado), puede producirse en ocasiones de manera violenta, airada y rupturista, en los límites de la costumbre y la convención. Vienen entonces las modificaciones que logran imponerse acompañadas, por lo general, de un fuerte componente simbólico que, a su vez, actúa externamente como pauta específica de identificación. Y aunque este proceder no es, concretamente en nuestra profesión, el modo más usual de comportarse aquellas transferencias y cambios profundos, y si bien en historiografía han sido pocas las transformaciones catalogables como de este tipo, ese fue sin embargo el caso transparente de los Annales en la vecina Francia, ése el origen de su excepcional fuerza de combate a favor de una epistemología renovada, y la razón, en fin, de su práctico impulso de sustitución, académica y disciplinar.

La mayoría de estas operaciones de transformación, en cada historiografía concreta, se lleva a cabo sin embargo de un modo muy distinto al que acabamos de enunciar. Los cambios se realizan gradualmente y de manera ecléctica, e incluso quedan acordados implícitamente bajo patrones varios de índole pactista y transaccional. $\mathrm{Y}$ a pesar de esto último, los cambios, por pequeños que sean, no dejan nunca de alterar la superficie de la profesión, variando las actitudes de los actores implicados en ellos desde abogar por nuevos modos de escribir la historia (aunque no lo sean tanto, en realidad, con tal de no abordar los problemas más hondos de epistemología), hasta la manifestación de temores muy serios - aunque posiblemente de apariencia trivial - en cuantos califican la más modesta modificación habida en superficie como algo peligroso o aberrante, supuestamente rechazable sin derecho a réplica, por venir revestida de implicaciones conflictivas, sin beneficio alguno o necesidad.

Hispania, LVII/A, múm. 198 (1998) 65-95 
2. Volvamos sin embargo ahora a esa transformación concreta de la historiografía española de la que aquí tratamos. Una mirada lanzada desde aquí, y atenta al fondo, permite percibir en la primera parte de los años 70 -por encima de ninguna otra cosa- que se está produciendo en la vida académica española relacionada con la historiografía, de una manera $u$ otra, un cambio de situación fundamental.

A mi modo de ver, consiste ese viraje en que la profesión recupera in extenso aquello que podríamos llamar la tensión del método. Y lo hace como una pauta básica de su proceso propio de crecimiento, tanto en extensión como en profundidad; un proceso que se da por sentado que es «normal» y a la vez. «necesarion, como parte de la modernización y normalización que se precisa como comunidad científica.

Al decir esto pretendo significar que, tras un eclipse largo, de nuevo se abre paso entre los historiadores españoles la preocupación por conocer --al menos algo- de los procesos de organización del conocimiento y la evidencia que toda ciencia contiene en sí, y sobre los que funda su reproducción. (No me interesa ahora el hecho indiscutible de que, visto en conjunto, el gremio de los historiadores españoles resulte sometido a esa tensión de manera incompleta o deficiente. Esa cuestión sin duda afecta a lo que afirmo en grado y cantidad, y sin duda tiene repercusiones evidentes. Pero sólo después querré volver sobre ella.)

Aquella reaparición de la preocupación metodológica en los historiadores constituye un indicio de regularidad y de homologación, después de un tiempo anómalo. Un tiempo largo que, con pocas excepciones, había estado repleto de silencios y mixtificaciones tremendamente burdas, de palabras vacías de toda realidad o lastradas por una mezcla espesa de odio y de ignorancia. En cualquier caso, el rescate de la preocupación metodológica puede considerarse, en buena parte, como algo relacionado con los niveles mínimos de respetabilidad y credibilidad ( científicas») inherentes a la organización de las comunidades profesionales y académicas, y no tanto con elementos dependientes de la ideologia o el credo político de los autores, de manera directa. Aunque aquellos factores no sean invisibles ni permanezcan en modo alguno inoperantes.

Porque la tensión de los métodos (aunque se nos olvide con frecuencia) es algo intrínseco, consustancial al discurso historiográfico moderno, hablando en términos generales; algo casi natural, podríamos decir, en el desarrollo normativo de nuestra disciplina y en el establecimiento institucional de sus «clásicos». Y algo, en fin, que no sólo erupciona precipitadamente en ciertos historiadores metafísicos que, por cualquier razón, tropiezan en su trabajo con "problemas", para ser finalmente desplazado sobre la mayoría, que reacciona con sorpresa o con desconcierto. No implica esa tensión, de modo necesario, crisis de identidad u otras alteraciones graves de la disciplina.

Por el contrario, forma parte esencial de la deriva misma de escuelas y tendencias en historiografía, de sus seguridades y flaquezas. Y aun refiriéndose quizá a un solo paradigma, han ido evidenciándose cambiantes sus supuestos de epistemología, a tenor de las modas filosóficas y azares del pensar propios del siglo xx. (Por más que sea a veces, en ocasiones críticas de ruptura de lími- 
tes entre los seguidores de una escuela, de corte radical y abrupto, inesperado, cuando aquella tensión metodológica se presente, obviamente, urgida de una inminente recuperación de las certezas o reclamando cambios con celeridad).

Dicha tensión procede en buena parte, conviene recordarlo, de las precupaciones -antiguas y legítimas, nada superficiales ni del todo resueltas-a propósito de cuáles debieran ser (cuáles son, en efecto) la naturaleza precisa y las funciones, los instrumentos y los límites propios, específicos, del conocimiento historiográfico. No sólo de cuáles puedan ser sus propiedades epistemológicas, sino también acerca de dónde comienzan a delimitarse otros campos afines, y qué interés o usos convenientes podrían derivarse de su vecindad.

Se trata, pues, de una manifestación intelectual constante y pluriforme, que aparece y se eclipsa alternativamente al menos desde la Ilustración, y que se hace presente en los ámbitos y latitudes todos -europeos y norteamericanos- donde han ido sedimentándose desde el positivismo las más potentes numéricamente ( $y$ por ello tambien las más originales) historiografías, poseedoras de las tradiciones de escuela más ricas y envidiables habidas hasta aquí.

Una presión interna que sube y se acrecienta con el tiempo, a medida que a su lado alcanzan forma y fuerza las autodefinidas como «ciencias sociales». En este caso, disciplinas conteniendo teorías diversas en su propio interior, casi siempre en competición - ya sea abierta o encubierta- con la historiografía. (Aunque la mayoría de las veces no llegue a producirse el choque de intereses, o el conflicto abierto, más que por contraste o negación, casi siempre debido a la elusión del tiempo como factor de análisis o al dilema teorico irresuelto entre lo general y lo particular).

Todas y cada una de esas ciencias sociales nacieron, a su vez, armadas de exigencias cognitivas y metodológicas (de explicación, de búsqueda de leyes, de generalidad), y bien dotadas de unos minuciosos rituales operacionales a escala práctica. Provistas, además, de nichos hacia afuera, con sus prolongaciones asímismo, para facilitar por este tipo de conductos la progresiva innovación. Carentes de un paradigma único, se han visto conducidas a concurrencias y retos permanentes entre enfoques teóricos, siendo a su vez origen de productos de síntesis que cada día aparecen más comunicados entre sí. Unos y otros, cada uno a su manera, pueden considerarse resultantes de la irresuelta pugna por conseguir, internamente a cada disciplina, el reconocimiento de la superioridad.

La experiencia directa, y particular, de esa tensión del método ha sido la causante de los mejores resultados a mi juicio en la historiografía, vista en su conjunto. Lo mismo si se inclina esa excelencia del lado clásico de lo particular, como si lleva a los historiadores a entrar en el objeto historiográfico desde la contrapuesta óptica de lo general. Siguiendo el hilo rojo que esa tensión denota -operación intelectiva que las ideas políticas y el afán ideológico pueden venir a reforzar quizá, pero nunca a suplir-, se me antoja más lúcida la discusión posible en torno a los problemas clave de la historiografía. También, si acaso -y puesto que una parte numerosa de nuestra profesión parece 
estar queriéndolo-, podría ser la fómula más técnica, la más útil quizá de abordar desde aquí, por nuestra parte, esos mismos problemas en su forma actual. Y por ello, ojalá, pudiera resultar un ejercicio colectivo fértil en cuanto a los acuerdos, incluso supraempíricos, formales a lograr ${ }^{6}$.

Volvamos, así pues, de nuevo hasta aquel punto de arranque cronológico que propusimos antes para el análisis de la historiografía española contemporaneísta. Y concédaseme que, incluso sin saberse o sin hacerse explícito, el reclamo del método va a ser en los 70 una tendencia casi general.

Conviene recordar que en su lugar será invocada a veces la teoria, no siempre bien delimitada como tal, no comprendida siempre en su especificidad frente a la metodología propiamente dicha y, finalmente, quizá identificada, reductoramente, con exigencias de encuadre y conceptualización derivadas del materialismo histórico. (En la práctica, en cambio, servida solamente con los principios de la cuantificación).

Esa tensión iba a hacerse patente con toda claridad a mediados de los años 70 y alcanzó su apogeo, como estrategia operacional, durante el tiempo aproximado de una década ${ }^{7}$. Ya fuese con carácter central y descarnado, radical, o como eco derivado de las modas foráneas, se materializaba muchas veces como tarea política, como una deuda contraída cara a la vida pública, en un esfuerzo de recuperar la memoria de un pueblo, de un grupo social arrinconado y, en suma, de un país. De una manera u otra, el reclamo del método se

6 Esa fue mi propuesta para analizar la incidencia de Tuñón en el contemporaneismo español (en la docencia media con carácter implícito) en un texto circunstancial y breve (1994): «Sobre historiografía española: Manuel Tuñón de Lara y la pasión del métodon, Hispania LIV/188: 11451153 , comentario al libro-homenaje citado en nota 4. Desde una perspectiva general, es también la idea-guía que se hace presente a lo largo de mi libro (1995): Los caminos de la Historia. Cuestiones de historiografia y método, Madrid, Síntesis.

7 Creo posible aventurar, no obstante, que, en cuanto al interés de los estudiantes, tiene que ver esta situación con el 68. Método y cientificidad (entendida aquí como carácter predictivo de la historia, especialmente de la contemporánea) tratan de disiparse como preocupaciones en el texto (lección inaugural de apertura de curso en el 69) de PALACIO ATARD, V. (1970): «Consideraciones sobre la investigación actual de nuestra historia contemporánea», en Ensayos de Historia contemporánea, Madrid, Iter Ediciones: 7-68. La influencia fundamental en todo este proceso corresponde desde luego al marxismo y, dentro de él, para Contemporánea, a la aglutinante tarea de Fontana. Pero han sido importantes, de una u otra manera, textos de aplicación concreta como, por ejemplo, el de VILAR, P., (1982): «Historia e historiografia de la guerra civil española. Algunas reflexiones metodológicas", en Brout, P., FRASER, R., y VILAR, P., Metodología histórica de la guerra y la revolución españolas, Barcelona, Fontamara.

Desde una orientación no marxista, la abundante obra de Ignacio Otábarri visa al comentario historiográfico más que a fa instrumentación metodológica. Véanse entre otros textos (1984): «En torno al objeto y carácter de la ciencia histórica»: Anuario Filosófico XVII: 157-172; (1985): "La recepción en España de la "revolución historiográfica del siglo xx"”, en La historiografía en Occidente desde 1945. II Conversaciones Internacionales de Historia: 87-109; (1987): "Les études d'histoire de l'historiographie espagnole contemporaine; état de la questions: Storia della Storiografia ll: 122-140; (1990): «El peso de la historiografia española en el conjunto de la historiografia occidental (1945-1989)", Hispania L/2, 175: 417-437.

Hispania, LVIII/1, nưm. 198 (1998) 65-95 
dibujó, por fin, como necesidad ineludible, en tanto que iría tomando formas diferentes, como producto natural de un incremento de intercambios entre las historiografías realizadas en España y de éstas, además, con las diversas escuelas de Occidente ${ }^{8}$. Poco a poco, pasó a considerarse un exponente de que había en España autores, con sus campos de estudio bien diferenciados, en busca del lógico contacto y de la conveniente difusión. De una manera u otra, hablar de metodologias (menos en cambio de la cuestión del método como un asunto de epistemología), volvió a raíz de entonces a ser algo usual.

No voy a detenerme ahora a argumentar por qué creo que decreció bastante esa misma tensión al alcanzarse la segunda mitad de los años 80 . Sin que ello signifique que después de la anterior renovación, volviese la despreocupacion anterior por la metodología (a pesar de rebrotes evidentes del menosprecio hacia esa discusión), sucede que la situación se estanca y cristaliza. No me parece muy aventurado arriesgar que ello ocurre, precisamente, porque se ha topado ya entonces con un cierto techo, porque se ha perfilado un modus vivendi que, de provisional, pasa a ser suficiente y satisfactorio para la mayoría.

Un techo que habrían contribuido sustancialmente a construir algunos manuales de inspiración marxista, la mayoría no escritos por autores españoles (Topolsky, Cardoso y Pérez Brignoli esencialmente, pero también Vilar), junto con ciertas reflexiones histórico-historiográficas de Fontana y varios ensayos socio-históricos de Tuñón, además de algún otro manual de rango más modesto, menos ambicioso en sus procedimientos y de usos y aplicaciones más concretos. (Aplicaciones que serían un tanto mecánicamente llevadas a la práctica, pero sin que esto les restase validez pragmática). Esos textos, juntamente con algún otro trabajo circunstancial destinado a la historia de la historiografía, lograrían satisfacer — si es cierta mi impresión- y casi por completo, toda preocupación de los autores españoles en el terreno que nos interesa. (Son pocos quienes desde Contemporánea, me parece a mí, absorvieron el esfuerzo extraordinario realizado en este sentido por colegas de otras cátedras o subdisciplinas, como es el caso de Eiras para la Moderna, por ejemplo).

Puede que sea útil algún día volver sobre una circunstancia de este tipo, y hacerlo con carácter estructural y colectivo, generacional, con tal de valorar a través de este prisma el estado actual de la obra historiográfica escrita, realizada, de una parte importante, al menos cuantitativamente, de nuestra profe-

\& Exponentes de que esa situación se hallaba cristalizada al doblarse la década de los 80 , en VÁzquez de Prada, V., OLABarri, I., y Floristán, A., eds. (1985): La historiografia en Occidente desde 1945. Actitudes, tendencias y problemas metodológicos, Pamplona, Eunsa. También en los articulos pioneros de Morales MoYA, A., (1983): «Sobre la historiografia actual»: Cuadernos de Historia Moderna y Contemporánea 4: 195-226; (1987): “Algunas consideraciones sobre la situación actual de los estudios históricos", en La (s) Otra (s) Historia (s) I, UNED de Bergara (Guipúzcoa) o, entre otros varios posteriores, (1993): "Biografia y narración en la historiografia actual», en VV. AA. Problemas actuales de la Historia. III Jornadas de Estudios Históricos, Salamanca, Universidad de Salamanca: 229-257.

Hixpantit. LVILV/I, núm. 198 (1998) 65-95 
sión. Han sido años, los ochenta, con muchas posibilidades individuales de institucionalización, con oportunidades numerosas de inserción y de ascenso en la profesión, a veces en un tiempo muy corto (al menos si contemplamos las cosas desde hoy, cuando se ha producido un claro retroceso general). Años que contuvieron muchas ocasiones - datables con gran exactitud, y muy continuadas- para seleccionar, al menos en principio, la excelencia de los profesionales a través de la pública cooptación, patente en oposiciones y concursos. Años que en su conjunto, en definitiva, son una época apropiada para mostrar cuál era, verdaderamente, el alcance real y la eficacia práctica de aquella tensión.

De la aproximación entre teoría y práctica, y del tipo de certidumbres metodológicas sostenido por los concursantes al profesorado universitario y a Ios puestos de investigación, podrán dar fe, si es que a ellos se acude, esos textos tan poco valorados que, sin recelo, llamamos «memorias». Textos heterogéneos en sus calidades y de interés muy diferente, a pesar de su aparente clonación; obras de un solo uso en tantas ocasiones y que, a pesar del importante objeto al que van destinadas, suelen ser descuidadas, significativamente, en su coherencia interna con la tarea cientifica particular a la que se supone que sustentan. (Independientemente de que sea posible o necesario demostrar su autoría o reafirmar, siquiera sea un momento, sus claves específicas de identificación).

No menos aleccionador resultaría el rastreo de esos mismos fundamentos de oficio y experiencia en tesis doctorales y tesinas. Terreno privilegiado, posiblemente, como ningún otro para la indagación acerca de las formas de aplicación de todo tipo de instrucciones teóricas y metodológicas, ya sean pocas - muchas, novedosas o no. Las pautas recibidas por los estudiosos principiantes, al tiempo de emprender una investigación (ya sea para una sola vez, ocasional y decisivamente, o para todo el recorrido de una cumplida vocación de historiador) y, quizá, sus modificaciones posteriores (sus variantes y sus préstamos, sus intercambios y giros estratégicos) no son irrelevantes, ni muchísimo menos, a la hora de captar las dimensiones reales de la incorporación a nuestra disciplina de patrones experimentales y teóricos venidos desde fuera. Y a la hora de interpretar también correctamente su particular adecuación a las fuentes usadas por los historiadores.

Y habría que rastrear en fin, con el mayor cuidado, las vías y maneras por las que dicha geometría, fija y estable en los años 80 , introduce sus vértices en la enseñanza media, al hilo de las reformas emprendidas por la Administración y de sus instrucciones pedagógicas, activando proyecciones didácticas, a veces muy confusos, de los aspectos más elementales de aquel cambio de objetos y de métodos. Y tratando, con ello, de dar respuesta a la necesidad de poner cierto orden en aquel magno encuentro, mil veces anunciado sin más aclaraciones, entre la historia y las ciencias sociales. (La polémica abierta en torno a las inaplazables correcciones en la senseñanza de las humanidades» demuestra bien qué poco se ha sabido, desde la política y desde la profesión, gobernar con cordura y con acierto aquella inevitable citación). 
Se daba por supuesta en esos días la intrínseca bondad de fomentar activamente la convergencia con otras disciplinas, vecinas o hermanadas con la historia. Al menos, eso se desprendía de los nuevos (y hoy en cambio ya "clásicos», por su parte, también) presupuestos de la historia social. Al contrario de lo que se supuso, sin embargo, era aquél un encuentro que sorprendía desprevenida a la inmensa mayoría de los actores implicados en la operación de modificación del saber historiográfico.

Implicaba cambios de estilo ésta, de vocabulario, de objetos y programas, cuando no de sujeto, en fin. Y en direcciones no siempre coincidentes. De manera que enseñantes y estudiosos de la historia se encontraron cogidos, atrapados, en un complicadísimo proceso de rechazo del positivismo historiográfico y del historicismo, de demolición de límites disciplinares y de convergencia epistemológica, todo ello a la vez, sin haberse provisto de cautelas ni mayor protección. Por lo general, para ser más precisos, se carecía de otros cortafuegos que los que, genericamente, ofrecía el marxismo. De ahí venía en la Contemporánea a buen seguro, más que de los Annales mismos directamente, aquella doble definición de la materia histórica, que por entonces volvía a presentarse como "nuevan: la historia como ciencia y, más concreta y especificamente, como ciencia social.

Aquel encuentro era a medio plazo, a pesar de su oportunidad, insoslayable, difícil de interiorizar y de asumir de una manera univoca, común, por los reproductores principales del sistema científico (los enseñantes en la universidad). Porque, ya en los 80 , sus esquemas internos de relación y choque no obedecían solamente -como podía haberlo sido, entre nosotros, diez años atrás - a esa propuesta doble y, al final, convergente: ciertos elementos de Annales y del marxismo combinados, en bastante medida compatibles entre sí como para dar forma, particular y extensa, a un cierto tipo de historia social que enlazaba sus supuestos teóricos en ciertas ocasiones, buscando incluso cerrarse mutuamente en sobre sí.

Poco a poco, aquel encuentro se había revestido de una pluralidad de opciones derivadas de la sociología y la antropología, mucho más obedientes a sus teorías respectivas. Resumiendo: se trataba de una brusca inmersión, de un abrazo agobiante en el caso español, en la compleja organización del territorio que acoge hoy - a finales de los años 90-a las humanidades y las ciencias sociales. Un territorio que se presenta a los observadores, paradójicamente, como uno y dividido a la vez, condominio compartido tanto como orgullosa propiedad particular. Y todo ello, además, en proporciones cambiantes y diversas, según los enfoques teóricos y las notaciones filosoficas de su fundamentación.

Aquella situación de la segunda mitad de los 80 , madurada y alterada después por algún que otro intento de clarificación sobre corrientes, escuelas y tendencias, evidencia el resurgir de una preocupación, partícipe o curiosa, por otras direcciones divergentes. Y no forzosamente prorroga la intención anterior de transitar por rutas de vocación holista y unidireccional.

Es todavía ésa la situación que desemboca a mediados de los años 90 en todo tipo de balances y diagnósticos, de horizontes diversos, que han ido pro- 
digándose, azuzados por la irrupción propagandística y un tanto interesada del supuesto "final de la Historia». Opinan a propósito - y esto es novedad-del estado de la historiografía en general, vista desde España.

De aquel interés, al parecer recuperado, por las cuestiones de teoría y método, han ido procediendo, dispersos mas crecientes, textos de orientación y factura diversas, en cualquier caso representativos de una reordenación que se halla en curso actualmente en la historiografía española -especialmente en Contemporánea, me parece a mi- respecto a lo que pueda dar de sí, a estas alturas, la tensión del método. Sintomáticos siempre se evidencian, aquellos textos y aquellos planteamientos, de que algo se ha movido muy en profundidad. Incluso reconociendo que domina en ellos el aire inacabado de las propuestas ofrecidas, la inspiración ecléctica o la imprecisión ".

Aunque los balances bibliográficos sectoriales y temáticos son ahora cada vez más frecuentes (Ayer, Historia Social o Historia Contemporánea han contribuido decididamente a hacerlos), está por realizar aún la revisión crítica y a fondo, es decir, contextualizadora y analítica, de cuál sea en efecto la incidencia real de los supuestos metodológicos invocados en las monografías sobre la obra historiográfica hecha, sobre la escritura de la historia conseguida. Operación que obliga, muy posiblemente, a particularizar las experiencias elegidas y a perseguirlas con detenimiento, con mucha vocación de microhistoriador o de lingüista, o incluso combinando ambas cosas a la vez. $\mathrm{Y}$ que también exige el recurrir a testimonios autobiográficos e introspectivos ${ }^{10}$, práctica entre nosotros no muy extendida. (Y aunque esto supone otro tipo de enfoque, habría que intentar realizar todo ello al tiempo que se cuida, simultáneamente, de valorar el peso y la circulación de la publicística académica corriente, en el ámbito al que se destina).

También haría falta por lo tanto una labor profunda de recapitulación a partir de las revistas especializadas, de sus líneas de edición y sus evoluciones, a medio y largo plazo. Tarea que no siempre es factible realizar con fruto en el marco emblemático de los aniversarios y las efemérides, ligados sobre todo

9 Merecen citarse en su conjunto los contenidos en Historia Contemporánea 7 (1992): «Historiografía contemporánea reciente»; ALVAREZ JUNCO, J., y JULIÁ, S., (1990): «Tendencias actuales y perspectivas de investigación en historia contemporánean: Tendencias en Historia, Madrid, UIMP/CSIC; RUEDA, G., ed. (1991): Doce estudios de Historiografia contemporánea, Universidad. de Cantabria, y Ruiz TORRES, P., ed. (1993): La historiografia (Ayer núm.12). Posterior es la panorámica general que ofrece GRANJA, J. L. de la, (1995): "La historiografia española reciente: un balance», en BARRos, C., ed. Historia a debate, Santiago de Compostela, $1: 299-307$. Muchos textos del l Congreso de Historia Contemporánea de España (Salamanca, 1992), dedicado específicamente al análisis historiográfico contemporaneísta (MORALEs, A. y EsTEBAN, M., eds. La Historia Contemporânea de España, Salamanca, Universidad de Salamanca, 1996) acusan claramente el retraso en su edición.

10 Materiales hay, sin ir más lejos, en VILAR, P., (1988): «Recuerdos y reflexiones sobre el oficio de un historiador»: Manuscrits diciembre: 9-33, y ToRTELLA, G, (1988): «El método del historiador: reflexiones autobiográficas", en GARCiA DELGADO, J. L., ed. La II República española. Bienio rectificador y Frente Popular, 1934-1936, Madrid, Siglo XXI: 241-248. 
a la vida de las instituciones y de las personalidades de excepción ". Una especie de índice comentado, que permitiera seguir en tanto el curso de los más importantes vehículos de difusión de las nuevas perspectivas científicas y de los resultados, sería muy útil ${ }^{12}$. Al menos hasta que se procediera, por poner un ejemplo, a esa lectura que reclamo, organizada según sus puntos fuertes y derivaciones. Sólo una aproximación de esa naturaleza a las revistas, en las diversas lenguas del Estado español, permitiría hablar, con mayor fundamento, del estado actual de nuestra profesón. Y de paso, quizá, tal ejercicio alcanzaría alguna posibilidad de predecir factores de futuro.

Claro está que contribuiría también sustancialmente a la movilización de recursos metodológicos el reforzar una tendencia que ya apunta con fuerza: la elaboración de análisis comparativos supranacionales, y de rastreos concretos de influencias precisas entre historiografías nacionales distintas ${ }^{13}$. Porque muestra ese esfuerzo, si bien se realiza, algo más que la existencia de buenas relaciones personales entre equipos de investigación de distintos países. Y es mucho más, este otro, que un entretenimiento erudito y periférico, hecho en beneficio sólo de unos cuantos historiadores que disfrutan de él. A mi modo de ver, aquella introspección resulta ser, en cambio, algo fundamental para el trazado básico y la cartografía particular de las diversas disciplinas científicas, cualesquiera que éstas sean; tanto como para la disección de su estado presente y para la prospección.

3. Llegados a este punto, y antes de continuar argumentando sobre lo que en efecto hay consolidado, conviene reparar en otra línea de «normalización» que delimita claramente el arranque de la situación historiográfica que ha ido siendo, hasta aquí, abocetada.

Lo que concede a la historiografía española que arranca de los años 70 su estatus de madurez científica, y lo que hace que entonces se le augure ya, con perspectivas de cumplirse el pronóstico, una existencia sana a medio plazo, tiene mucho que ver, indiscutiblemente, con el proceso de institucionalización y consolidación de las denominadas historiografías sectoriales. De manera muy especial, es forzoso mencionar la existencia en España de una vivaz historia económica que, desde la fundamentación sociocientífica que

$"$ Las revistas del CSIC (Arbor, Hispania o Revista de Indias) han aprovechado su cincuentenario para propiciar introspecciones, más o menos críticas. Una aproximación general, por ejemplo, en ALMUINA, C., y otros (1990): “"Hispania", revista de Historia (1940-1989). Análisis y evolución de contenidos", en Cincuenta años de historiografia española y americanista (monográfico Hispania $\mathrm{L} / 2,175$ ): 393-416.

12 Una información breve y útil sobre las revistas académicas españolas de Historia Contemporánea en MORadielios, E., (1996): «Contemporary Spanish History Journals: an Overview»: Contemporary European History 5/2: 267-271.

13 Distintos ejemplos en Grohman, A., ed. (1991): Due storiografie economiche a confronto; Italia e Spagna dagli anni'60 agli anni'80, EgeA, Milán, y GABRIEL, P., y UCELAY, E., (1992): «E] impacto de la historiografia contemporánea italiana en la españolan: Spagna Contemporanea 1: 127-135.

Hispania, LVIII/I, núm. 198 (1998) 65-95 
para ella exigiera Vicens ${ }^{14}$ en los años 50 , hasta la actualidad, tras pasar unas décadas de orientación teórica de plural dirección, ha realizado su travesía del desierto de una manera válida, técnicamente impecable.

La historia económica que hay entre nosotros, trascendiendo fronteras y periodizaciones, acoplada a los espacios y a los ritmos propios de la teoría económica - la cual debe guiarla en cualquier caso, sea cual fuere su opción-, ha abordado con éxito el desarrollo y la organización de una comunidad cientifica que sin duda se muestra, comparativamente, internamente fuerte y asentada, homologable a otras equivalentes de su entorno inmediato, en el exterior. Y que se ha convertido de este modo, y se explica enseguida el por qué, en la más internacional de las historias sectoriales que tenemos. (Lo cual no quiere decir, sino todo lo contrario, que de vez en cuando no se halle abocada su familia a la inevitable discusión sobre objetos y métodos).

Como efecto indirecto de esa prosperidad y de esa autonomía sectoriales, ha venido a autoconsiderarse (las excepciones son particulares) una manera de escribir historia prácticamente ajena a otros posibles escenarios de discusión metódica. Se abre así, de este modo, una primera brecha -creciente y silenciosa las más de las veces; otras, las menos, acompañada circunstancialmente de un eco o un clamor- entre los historiadores económicos y el resto entero de los historiadores, una fractura al margen de otros esfuerzos interdisciplinares, permaneciendo ajenos sus especialistas a otros intentos de superación -dados seguramente ya por imposibles o por innecesarios- de los internos límites, y las fragmentaciones, que acarrea la especialización. A ritmo rápido, con autocomplacencia, esta historia económica ha ido estableciendo, también entre nosotros, un modelo constante de autorreflexión -historiográfica y metodológica - similar al que es propio de contextos científicos de alcance equiparable ${ }^{15}$, compartiendo las características de la Europa

14 Vıcens, J., (1954): «Hacia una historia económica de España. Nota metodólogican: Hispania XIV/LVIJ: 499-510, una crítica a diversos ensayos sobre la decadencia económica de España. Y, de paso, un manifiesto metodológico inaugural.

15 Por muy larga que venga a resultar esta referencia — que tampoco se pretende exhaustiva-, es preciso citar: Pérez MoRedA, V., (1975): "The Journal "Moneda y Crédito" and its Contribution to Spanish Historiography, 1942-1974m: The Joumal of European Economic History 4: 753-788; ARACli, R., y GARCla BoNAFÉ, M., (1978): «La història econòmica de l'Espanya contemporània fins a la guerra civil: principals aportacions»: Recerques 8: 207-220; TORTELLA, G., (1980): «La historia económica de los siglos XIX y XX: ensayo bibliográfico", en TUŃ́̇ DE LARA, M., y otros, Historiografia..., 175-206; PRADOS, L. (1984): «La historia cuantitativa en España»: Revista de Historia Económica 1I/1: 169-176; VV. AA. Papeles de Economia Española núm. 20 (1984): «La nueva cara de la historia económica en Españan; MARTí ACENA, P., y PRADOs, L., eds. (1985): La nueva historia económica en España, Madrid, Tecnos; BusTELO, F., (1985): «La nueva cara de la historia económica de España (I)»: Revista de Historia Econónica III/3: 419-439 y (1986): «La nueva cara de la historia económica de España (II)m: Revista de Historia Económica IV/2: 267-294; CoMiN, F., (1985): «Informática, estadística e historia económica en España: un balance»: Revista de Historia Económica III-3: 393-4 18; VÁZQUEZ DE PRADA, V., (1990): «La historia económica en España (1940-1989): Esbozo de su nacimiento y desarrollo»: Hispania L/2 (175): 473-487; S. Coll (1991): «La nueva historia económica y su influencia en España», en RUEDA, G., ed. Doce estudios..., 69-117; TORTELLA,

\footnotetext{
Hixpania. LVIII/t, núm. 198 (1998) 65-95
} 
mediterránea muy en particular. Y, como era obligado, lo ha hecho en discusión -real o imaginaria - con su horizonte teórico disciplinar, un horizonte claramente marcado por la deriva secular de la ciencia económica y sus doctrinas propias, sujeto estrechamente a sus hegemonías, a sus modas y a sus tributos ideológicos también.

De esa historia económica va ahora derivándose, cada vez más precisa y más articulada, la "historia empresarial" ${ }^{16}$. Una nueva manera de enfocar integral, socioculturalmente, el estudio de la organización económica de los países industriales. Dispuesta en ocasiones a reforzar una "historia del trabajo» armada (quizá más en los métodos que en su propio objeto, por lo que se vé) a la manera anglosajona. Entre tanto, se aviene a seguir transitando también por sus espacios propios -en Cataluña muy especialmente- aquella otra forma de historia económica que a veces se englobaba en la historia social y que continúa reivindicando la etiqueta (podríamos decir que un poco más clásica) de "historia industrial».

No pretendo sin embargo traer aquí, una a una, al resto de las especializaciones y corrientes. Pero me arriesgaré a aventurar alguna consideración particular a propósito del catálogo de especializaciones "nuevas», con propia

G., (1991): «Las causas del atraso económico en la historiografia: un ensayo bibliográfico sobre la España del siglo Xix con algunas comparaciones con los casos de Italia y Portugaln, en GroHManN, A., ed. Due storiografie..., 189-228; BARCIELA, C., (1991): «La historiografía sobre la economía española del siglo XXı, en Grohmann, A., ed. Due storiografie..., 229-258; Martin ACEÑA, P. (1993): "La historia económica contemporánea: raices y perspectivas», en SANCHEZ NISTAL, J. M., y otros, Problemas actuales de la historia, Salamanca: 189-198; MARTiN ACEÑA, P., (1993): «La historia econónica contemporánea: raíces y perspectivas", en MonTanart, M., y otros, Problemas actuales de la Historia. III Jornadas de Estudios Históricos, Salamanca: 189-198; NADAL, J., y SuDRIA, C., (1993): "La controversia en torno al atraso económico español en la segunda mitad del siglo XIX (18601913)», Revista de Historia Industrial 3: 199-227.

16 VALDAliso, J. M., (1993): «Algunas reflexiones acerca de la historia empresarial y su desarrollo en Españan: Revista de Historia Económica XI/2: 417-433; ToRTELLA, G., (1993): "Comentario a las reflexiones sobre la historia empresarial del profesor Valdalison: Revista de Historia Económica XI/3: 623-625; CoLL, S., (1993): «El profesor Valdaliso, a vueltas con la historia de ia empresan: Revista de Historia Económica XI/3: 627-630; Fralle, P., (1993): «La historia económica de la empresa como disciplina independiente: una perspectiva histórican: Revista de Historia Económica XI/1: 181-192; NúÑEZ, G., y SEGRETO, L., eds. (1994): Introducción a la historia de la empresa en España, Madrid, Abacus; CoLl, S., y ToRTELLA, G., (1994): «Reflexiones sobre la historia empresarial: estado de la cuestión en España», en NúÑEZ, G., y SEGRETo, L., 67-87; SEGRETO, L., (1994): «De la historia económica a la historia de la empresa: la marcha del debate en España», en NúNez, G., y Segreto, L., 17-37; Torres Villanueva, E., y Puig Raposo, N., (1994): «Panorama general de la historia empresarial en Españan, en NúNEZZ, G., y SEGRETo, L., 39-65; MARTinez RuIz, J. I., (1995): «Historia empresarial e historia del trabajo: del aislamiento a la colaboración»: Revista de Historia Económica XIIL/2: 331-345; Comin, F., y MARTiN ACENA, P., eds. (1996): La empresa en la Historia de España, Madrid, Civitas.

Para la demografia histórica, además del trabajo citado en nota 4 , véase PÉrez MoReda, V., (1996): «Veintícinco años de demografia histórica», en Gómez MENDOZA, A., coord. Economía y sociedad en la España Moderna y Contemporánea, Madrid, Síntesis: 277-297.

Hispania, LVIL/I, núm. 198 (1998) 65-95 
autonomía, que a veces se enumera. La mayoría no pueden equipararse todavía en producción, y en organización, con esta otra que acabamos de particularizar, la historia económica. Aunque parece ya cumplido, en cualquier caso, al menos el primero de los encargos de Jaume Vicens, cuando en una "Nota metodológica", publicada en Hispania en la fecha de 1954, verí́a a decir: "En general, los historiadores vamos ufanos y vendidos por la senda de nuestros entusiasmos. Esculpimos en el vacío o nos entretenemos en describir epidermis. Es preciso ir al meollo de la cuestión, que sólo podemos procurarnos partiendo de estos dos principios fundamentales: historia económica, de un lado; historia de la mentalidad social, del otron.

En cuanto al segundo de estos dos principios no ha sido nada fácil llegar a establecer un punto de convergencia principal. Pero por lo que se refiere al primero de ellos, la pista de despegue ha parecido funcionar durante todo el tiempo, sin interrupción.

4. Hay sin embargo también en nuestro suelo una «historia urbana» y una "historia rural", una "historia de las ciencias" (repartida a su vez por las distintas disciplinas), lo mismo que una «historia de la educación», una «historia de la cultura" (con sus dificultades específicas de realización), una "historia de las relaciones internacionales" (ya no la misma cosa que una «historia de la política exterior», ésta a su vez planteada como superación de una añeja «historia diplomática», que a veces se evidencia sin embargo, paradójicamente, desconocer...). Además de unas (siempre nuevas) «historia de la vida cotidiana» e "historia oral», "historia de las mujeres" e "historia de las relaciones de género". Está incluso la que aparenta ser la más novedosa de todas quizá, la "historia reciente», propuesta por su parte ya no tan sólo como una forma más de la (renovada) "historia política». La cual, siguiendo situada ciertamente en el centro de la profesión a pesar del empuje de la historia social, ha vuelto a reclamar algunas veces ser la única historia, y muchas más aún, no ha consentido de ninguna manera en dejar de ser la forma principal. (Con todo lo anterior, como bien se conoce, no hernos agotado todavía los historiadores el elenco de posibilidades y de opciones, ésa es la verdad).

Cada una de esas historias sectoriales (que en su marchamo de novedad incluyen normalmente la etiqueta de avales e influencias diversas llegadas desde el extranjero) presenta, sin embargo, sus propias coordenadas. De un lado, resultan ser producto derivado del auge interactivo de las inspiraciones exteriores. De otro, obedecen indirectamente a las características inscritas en las condiciones generales de posibilidad de una situacion historiográfica dada (en este caso, la española en general o, mejor, cada una de su parcelas y zonas especificas). Es decir, dependen de cuáles sean las notas definitorias del contexto en el que se originan - aquéllos y no otros - los concretos esfuerzos intentados por los historiadores, en pro de una sectorialización disciplinar.

Lo cual viene a plantear un problema a su vez: ¿pueden localizarse características compartidas y comunes, con sus modelos internacionales, por ejemplo, en el supuesto arraigo entre nosotros de una llamada "historia de las mentalidades», o de una "historia cultural", sea ésta, finalmente, lo que 
fuere...? Convendría discutirlo alguna vez. Reconstruyendo de paso trayectorias tan dispares como la de la "historia intelectual», la «historia popular», o la shistoria de la familia». Y quizá todavía, por mucho que esta otra operación introspectiva pueda acaso enojarmos, volver a discutir en qué consiste esa variada suma de productos interpretativos que, todavía, no hemos sabido llamar de otra manera que "historia social»... 17.

Imposible resulta, a mi modo de ver, decir algo sensato y valedero respecto a todo ello, si es que no convenimos en entrar finalmente, a fondo y sin pereza, en un tema importante: el de la relación (irreversible a mi modo de ver, nos convenza ésta o no) entre la historia y las ciencias sociales. Relación que es producto de una constante y multidireccional operación de confluencia y delimitación en las fronteras de la epistemología, y que se halla en marcha desde hace mucho tiempo, sin parar. Ha adoptado hasta aquí, en esa trayectoria, muchas formas y maneras diversas, en una especie de conflicto permanente, dando así fondo y forma a una aventura intelectual que no es nada reciente, ni coyuntural, aun cuando sus confluencias más operativas a esta hora - no sus oposiciones más radicalizadas, quizá por el contrario- se daten, sobre todo, de los años 70 para acá.

Se trata de un asunto sobre el que hay ya, por cierto, un material bastante -incluso en castellano- como para entender, con ciertas garantías, la trayectoria múltiple que ha dado lugar a la presente situación. Esa es también, a no dudarlo, la posición más favorable para hacer el balance contextualizado de una "historia oral» y, muy en especial, de una «historia de las relaciones de género». Ambas, maneras extraordinariamente sugerentes, no siempre independientes entre sí, de escribir la historia (las historias) y de interpretar la vida y la experiencia. Que han sido básicamente alimentadas por una conceptualización llegada en primer término de otras disciplinas: de la sociología, la antropología, la psicología o la lingüística, muy en especial. Y, también, que se ven muy pendientes en su evolución y en sus pautas normativas de aquello que ha sido producido en otras latitudes y medios académicos, cuyos enfoques y significados se materializan sobre todo en inglés. Son, todos ellos, acercamientos de índole siempre mezclada y transdisciplinar. Y, por eso, el previo gobierno de sus claves teóricas y de sus instrumentos, antes de poner manos a

17 Con alguna incursión suplementaria (Forcadell, por ejemplo) la parte sustancial de este debate se debe, entre nosotros, a Julián Casanova y a Santos Juliá, muy especialmente. Del último sólo cito aqui algunos de los textos de más repercusión: «La historia social y la historiografja española», Ayer 10 (1993): 29-46 y otro del mismo título, revisado, en MORALES, A., y EsTEBAN, M., eds. (1996): 183-196. DE CASANOVA (1991): La historia social y los historiadores, ¿cenicienta o princesa?, Barcelona, Critica. Apéndice sobre historia social española: 159-166. También GABRIEL, P., (1995): «A vueltas y revueltas con la historia social obrera en España. Historia obrera, historia popular e historia contemporánean: Historia Social 22: 43-55 y el colectivo hispano-francés (elaborado en Pau, 1993): L'Histoire Sociale en débat (Bulletin d'Histoire Contemporaine de l'Espagne núms. 17-18). Convendria, a su vez, analizar la trayectoria metodológica de los estudios propiciados por la Asociación de Historia Social. Las actas del II Congreso (Córdoba, abril de 1995) en CASTiLlo, S., coord. (1996): El trabajo a través de la Historia, Madrid, CEH-UGT/AHS.

Hispania, LVIII/, núm. 198 (1998) 65-95 
la obra, es del todo preciso para el historiador, si es que queremos disminuir el riesgo de no avanzar un paso y ahorrarnos la caída en la trivialidad.

Mis reparos a propósito de la deficiente manipulación y el frágil dominio que pueden observarse entre nosotros, hablando en general, a propósito de las teorías y las metodologías que subyacen sistemáticamente a los nuevos enfoques (las cuales han de importarse juntamente con la elección temática, desde su formulación originaria hasta la adecuación concreta a sus usos aplicados), no se agotan ahí.

En el caso de la «historia de la vida cotidiana", por ejemplo, variará desde luego la perspectiva utilizada de elegirse previamente cualquiera de los enfoques interaccionistas (bien sea éste goffmaniano o bien simbólico, puesto que ambos no son, por cierto, mecanismos idénticos de operación). A no ser que, por hablar de otra influencia más cercana, quiera el autor de un trabajo de este tipo considerarse seguidor de Lüdtke, uno de los pocos en lengua alemana que disponen de textos editados aquí.

En términos generales, parece una constante en nuestra profesión la recurrencia fácil a esa elusión teórica, cuando no al camuflaje. Una elusión que viene a ser de inmensas repercusiones conceptuales y retóricas en cuanto a la calidad media de la producción. y que, en contra de lo que se supone muchas veces, tampoco es especialmente favorecedora del trato concedido a la empiria. En la historiografía que puede ser considerada de factura más tradicional, los enfoques teóricos implícitos - siempre existentes- quedan sin embargo eximidos de mayor aclaración, no pareciendo a nadie, a estas alturas, necesaria ni mayor transparencia ni explicitación. Pero en las operaciones de innovación historiográfica que abogan por el rescate del sujeto individual -aun incluso comprendido en su medio, inserto en su diaria negociación--, y de la experiencia vivida (operaciones de signo filosófico a la vez muy distinto entre sí), casi todas ellas directamente involucradas en los conflictos multiparadigmáticos de las ciencias sociales, esa carencia puede llegar a ser un encubierto fraude. Afortunadamente para nuestro gremio, sin embargo, no siempre llega a producir efectos desastrosos, dependiendo al final el resultado de la sensibilidad y las capacidades comprensivas de los autores y de su particular habilidad, de su experiencia acaso para interrogar a las fuentes empleadas y llegar a construir un relato.

Pero no se trata, ni muchísimo menos, de difundir la alarma o la condena en los márgenes nuevos que alcanza la materia historiográfica, debilitando las fuerzas destacadas en las fronteras de su interconexión con la sociología o la antropología. En modo alguno es ésa mi intención. Reclamo sin embargo un cuidado exquisito. Y trato de alertar sobre lo impropio de caer en excesos, allá donde los haya, de autosatisfacción.

En mi opinión, aquella penuria filosófica estorba en ocasiones incluso el crédito que solicita para sí - y que se le otorga sin discusión visible, en una especie de giro circular- la que se autodefine "nueva historia política» española (aunque no haya explicado nadie, que yo sepa, por qué lo es). Algo menos quizá, permite esa carencia sospechar cuáles son las fisuras que amenazan incluso en la denominada "prosopografía", presentada a su vez como modo y 
manera de interconectar, por medio de lo múltiple y sin perder de vista lo particular, una "historia política" y una "historia social".

Solamente una desgana sistemática en cuanto a la definición de los métodos utilizados, debidos a su vez a precisas teorías (no vale, en su defecto, con declaraciones más o menos nuevas a propósito de la trascendencia de ambos), o una genérica indefinición ante los supuestos precisos y concretos -y ante las exigencias instrumentales - de su aplicación, puede haber conducido a proclamar a algún colega que, al lado mismo de las historias usectoriales» que enuncié más arriba, apuntan o prometen otras «novedades» historiográficas diversas, merecedoras del mismo rango y consideración que tienen las anteriores, y por eso constitutivas, sorprendentemente, de subgéneros particularizados.

Lo más preocupante no llega a ser, con todo, el hecho de que el balance del descubrimiento, hace unos pocos años, de la fragmentación --por otra parte, un despiece o una refracción, inevitablemente fomentados por las propias trayectorias de la especialización- haya sido encauzado hacia un conjunto heterogéneo de discusiones académicas, mejor o peor fundamentadas, en torno a la denominada "nueva historia", sin llegar a aclararse mucho la situación. Lo peor, creo yo, es que, rizando el rizo de las novedades, se halla una percepción insuficiente entre nosotros de la naturaleza filosófica de las dificultades, una incorrecta apreciación, muchas veces, del escepticismo cognitivo que se columpia en la denominada "posmodernidad». Lo cual conduce a muchos de nosotros a más de una valoración equivocada, precipitada acaso, a propósito de un asunto central en la tarea historiográfica, consustancial a su naturaleza hermenéutica y al carácter retórico de la interpretación, condensado en el relato. (Cuya relación íntima con la denominada "vuelta del sujeto" no es, necesariamente, la que parece haber predominado hasta hace poco en la retina colectiva de los historiadores españoles, lo cual, por otra parte, deja al descubierto que no es nuestro fuerte ni la filosofía poskantiana ni, muchísimo menos, la lingüística).

5. La percepción de la "crisis" actual por los historiadores españoles (al menos en lo que se refiere a la Contemporánea: conviene que insistamos, todavía una vez, en que este es, por fuerza, el punto de partida de mi valoración) ha venido acompañada, entre aquellas otras novedades de distinto alcance, del rearme de la «historia política». Un rearme por lo general se ha considerado acertado y eficaz, hablando en términos funcionales y pragmáticos.

¡Qué duda cabe de que lo político y la política nos interesan muy especialmente a los historiadores, al menos en la mayor parte de sus expresiones! No es preciso que insistamos más en este punto. Pero, aunque no se acostumbre a reparar en ello, es precisamente en la historia política hecha desde España (se llame "nueva" o no) en donde las fronteras y las limitaciones de la disciplina pueden llegar, a veces, a ser más evidentes. Donde se transparentan, así pues, antiguas insuficiencias estratégicas y quedan al descubierto los puntos más oscuros, las aristas más frágiles y descascarilladas de un tipo de discurso, de aspecto romo y tradicional, que ha cambiado muy poco desde hace un siglo acá.

Hispania, LV]IU/, núm. 198 (1998) 65-95 
Para no dedicarle ahora a este asunto crucial más que unas pocas líneas, sólo enumeraré algunas de las flaquezas evidentes de aquello que se ha presentado en ocasiones como un "rescate» o "recuperación"; es decir, la supuestamente debida restitución de la historia política en el seno del contemporaneísmo español, una vez terminado con éxito el combate contra un ilegítimo, aplastante predominio de la historia social. (Traslación indebida a nuestro suelo, me parece esta batalla a mí, a su vez; o conclusión apresurada al menos, obtenida a partir de la forma específica en que se han producido en la vecina Francia, en la última década, cambios historiográficos, en coincidencia con el declive extenso de la historiografía vinculada al marxismo, incluso en Inglaterra). Según esto, la historia política habría quedado en la España posfranquista también acorralada e indefensa. Y ahora, en cambio, renacería triunfal.

A no dudarlo, se impone un correctivo para un balance tan liviano como inexacto. Sería preciso rechazar, ante todo, la tenaz persistencia de reflejos miméticos, derivados de polémicas historiográficas transpirenaicas que reverberan en la presentación de ese "retorno" imaginario, inadecuado a lo que aquí sucedió. Lo cual no significa sin embargo el rechazo de la comparación. En cambio, aclararía mucho el cubrir de verdad un hueco antiguo, puesto que no se corresponde este otro esfuerzo, en términos globales, con una estricta novedad. Se ha escrito hasta hoy mismo muy poco ${ }^{18}$, en resumidas cuentas. sobre qué cosa sea la "historia reciente», no sólo en su vertiente temática y cronológica sino, ante todo, en su fundamentación metodológica y teórica. (Ya puestos, me gustaría conocer también la opinión de los historiadores españoles a propósito de sus bases filosóficas, nada despreciables).

Poco hemos discutido, en efecto, respecto a cómo ciertas modalidades de eso que se llama también "historia del presente» tratan de transformar la percepción, por el historiador, de la política y de la cultura como procesos imbricados en la experiencia del sujeto, como facetas de la realidad inseparablemente concebidas. Y cómo se proponen dichos enfoques impulsar esa transformación en cuanto a sus manifestaciones explícitas y dichas, intersubjetivas y situacionales, a la vez que ahondarían en sus prolongaciones más imperceptibles, calladas o secretas, en sus vericuetos más íntimos y, por ello, inefables. Quizá por lo tanto intransferibles, de no ser por la aprehensión significativa de fragmentos que componen los universos simbolicos, cuyos elementos hay que romper y desentrañar.

Los referentes sociocientíficos y filosóficos que soportan -en cada historiografía nacional de manera distinta y, en consecuencia, siempre relativa-

Is CUESTA, Josefina, (1993): Historia del presente, Madrid, Eudema y (I995): «De la memoria a la historia», en ALTED, A., coord. Entre el pasado y el presente. Historia y memoria, Madrid, UNED: 57-88. Los textos del Seminario Complutense sobre ese mismo objeto organizado en el otoño de 1997, por J. Aróstegui, en la Universidad Complutense no han sido editados aún.

No debe olvidarse, sin embargo, que la noticia de una «historia del presente» obligada a diferenciarse de la Contemporánea está ya, por ejemplo, en PALAClo ATARD, V., (1970): "Consideraciones sobre la investigación...», 43 ss., sin que el autor llegue del todo a pronunciarse sobre esa divisoria que proponía entonces la nueva historiografia. 
esa especial operación de aprendizaje y de conocimiento, intentada esta vez desde la disciplina de la historia no son, desde luego, ajenos (y ni siquiera periféricos o accidentales podrían llegar a ser) a ese nuevo horizonte mixtilíneo del historiador. Un horizonte que ha quedado ya para siempre abierto y fluctuante -en mi opinión, insisto de modo irreversible- a través del contacto permanente de la historia con las ciencias sociales.

Del potencial nacido de esa franca ruptura podría derivarse - acaso se ha derivado a estas alturas ya- una importante parte del capital futuro de nuestra disciplina como especialidad, como cadena de códigos y pautas de conducta disciplinar inscrita en la academia, o como vía de conocimiento y praxis cognitiva, lo cual parece más importante aun. Puede que a medio plazo (y no ahora todavía, cuando es tan bienvenida la abundancia innegable, exuberante, de publicaciones y de títulos), se llegue a percibir con claridad la excesiva ligereza en el análisis y en la explicación con que a veces se aborda el pasado reciente. Ajenos la mayoría de nosotros, de modo sorprendente, a cualquier perspectiva de análisis que pueda comportar derivaciones significativas o atención a los efectos de la mediación, impasibles ante cualquier lectura que no se diga directamente derivada, nacida y contenida, en el escudriñarse mismo de los documentos (lo mismo da, en feliz paradoja, que sean éstos orales o escritos), parece incomodarnos además oir hablar siquiera de las limitaciones evidentes, del desconcierto acaso, que transporta consigo toda interpretación.

Con frecuencia es trasladado este planteamiento, como tenía que ser, al plano de la crítica historiográfica. Una tarea específica mal configurada aún como género propio, lastrada en su valor no sólo por el objetivismo y el realismo más crudos, sino por servidumbres y deficiencias viejas, muchas veces más temibles aún. Son frecuentes en ella la imprecisión y el apresuramiento, posiblemente utilizados, en uno y otro caso, como un sustituto amable de la exigible crítica y ponderación. Y véase, si no, el tono laudatorio desproporcionado de muchos de esos textos, y la factura desarticulada de la mayoría de nuestras reflexiones y reseñas críticas, junto a la liviandad ayuna de contexto de tanto comentario bibliográfico, de alguna extensa nota o incluso boletín ${ }^{19}$.

Facilitada, desde luego, esta dinámica por la abundante publicística sobre el inmediato pasado español que las dos últimas décadas han permitido pre-

19 Digno de reparar el apresuramiento de ciertos textos de TuSELL, J., patente ya en los títulos («La dictadura de Franco a los cien años de su muerte» (sic), en Fusı, J. P., ed. (1993) La historia en el 92, Ayer 10: 13-28), tanto como en una manera de hacer que con frecuencia es carente de reposo, que no de información. Así ocurre con textos apresurados, como la biografía política de Antonio Maura del propio Tusell (1994, Alianza editorial), un libro prescindible del todo a pesar de incorporar documentos inéditos, a los que apenas se tomó el historiador el tiempo mínimo para interrogar.

En general, no obstante, la valoración de la historiografia sobre Franco y el franquismo no ha carecido de suerte: por ejemplo, ARóstegut, J., (1992): "La historiografía sobre la Esparĩa de Franco. Promesas y debilidades»: Historia Contemporánea 7: 77-100; PÉREz LEDESMA, M., (1994): «Una dictadura "por la gracia de Dios"»: Historia Social 20: 173-193.

Hisprania, LVIIIII, nบ่m, 198 (1998) 65-95 
senciar; derivada a su vez aquella publicística, en proporción notable, de conmemoraciones variadas y de un culto sin cribas (cribas «cientificas", me apresuro a añadir) a ese concepto blando que es 'la memoria histórica', se da la circunstancia - circunstancia añadida - de que, entre tanto, no parece cuajar entre nosotros, de modo suficiente, el género biográfico. (Aunque haya quien opine lo contrario, no considero indicios suficientes el éxito indudable alcanzado por unos cuantos títulos espléndidos, de especial agudeza y calidad),

Pero no es paradójico un hecho de tal índole, me atrevo a suponer. Y puede que, en el fondo, tenga igual relación con aquella carencia reflexiva en tomo al estatuto de la historia que, en nuestro oficio, vengo señalando. A pesar de algún título emblemático y a pesar de los recuentos optimistas que miran sobre todo a aquellos rasgos que nos asemejan a nuestros vecinos (por fin apuntaría entre nosotros, según este supuesto, rompiendo "viejos" moldes de impronta "cientifista", aquel género histórico que, como ningún otro, se centra sobre lo particular), lo cierto es que la biografía, como género vivo, no acaba de cuajar.

Tiene tal cosa posible traslación a un contexto más amplio, donde estaría en relación profunda con la inconsistencia y el capricho con que, a veces, hemos hablado del papel del «sujeto" en historiografía, de su vuelta o retorno, de la correspondencia estrecha de aquella vuelta con la narración. Pero, también, entraría en relación con otras circunstancias ambientales, en deuda con las concretas condiciones de posibilidad ligadas, acaso inseparablemente, al proceso político de la transición. Me referiré de inmediato, para aclararlo un poco, a una de las características intelectuales de aquel proceso que me parecen más decisivas.

Una cierta inclinación circunstancial a lo que podría llamarse -y sé que es un mal nombre- "historiografía periodística» se perfilaba entonces. Nutrida con el afán urgente de conseguir un acrecentamiento múltiple de la "investigación", era entendida como "descubrimiento", ininterrumpido, de fuentes nuevas o de documentos hasta ahí clausurados e inaccesibles al historiador. Esa tendencia ha podido acompañar, doblándose tal vez una función con otra $-\mathrm{y}$, cosa más importante, marcando un "estilo" de análisis y evaluación histórica que, al menos hasta cierto punto, gusta y se.imita suficientemente-, a la práctica política de algún historiador. No creo sin embargo que sea esa misma práctica el motivo de las debilidades y carencias que se derivan de ese proceder. Sino la elusión reiterada, y voluntaria al fin, de cierto grado, siempre necesario, de discusión metódica sobre los fundamentos y circunstancias críticas de la disciplina. La elusión no infrecuente, en resumidas cuentas, del ejercicio de pararse a pensar.

Que en nada estorba aquella discusión metodológica - sino que, al contrario, la sostiene- a una gestión cuidada, atractiva en su forma y rigurosa en sus técnicas, de la masa cada vez más importante de la empiria. Pues contribuye sustantivamente a otorgar cuerpo y estructuración a la retícula que van trabando poco a poco las informaciones, forjando las preguntas más allá (o más acá) de las supuestas intenciones aleatorias y particulares de los actores 
y los protagonistas. Intenciones que, de hacer caso a la valoración de algún especialista, resultarían ser completamente ajenas al contexto, independientes entre sí de modo virtual. (Más que una moda, parece una catástrofe).

Hay otros elementos coadyuvantes que en nada favorecen, mirando a ciertos campos y ámbitos sectoriales, previsiones de futuro mucho más optimistas. Reforzaría, muy posiblemente, esa fragilidad un cierto debilitamiento (en proporción cuantitativa y en influjo, ambas cosas a la vez) de la consideración historiográfica, antes fundamental, de los autores extranjeros atraídos por España. (Eso que genéricamente denominamos "hispanismo": la "mirada del otros cargada de razones, de retos y de complicidades a la vez, y que contribuye decisivamente a la construcción misma de las identidades nacionales y a su representación).

Asunto por tratar seguramente, éste de la pérdida de peso relativa de los autores extranjeros, se trata de una cosa hasta cierto punto natural, a medida que ha ido consolidándose la comunidad historiográfica nacional-estatal propiamente dicha. En cualquier caso, conviene ya decir que eso que puede considerarse como un descenso estable de la importancia relativa de las escuelas y de los nombres propios (más quizá, en lo que se refiere a la Contemporánea, de los franceses que de los británicos, hablando ahora comparativamente) debería matizarse mucho, para ser más exactos, teniendo en cuenta la progresiva incorporación a la tarea de otros «hispanistas», de procedencia varia: alemanes e italianos, muy principalmente. Y, de modo más adecuado aún, debería atemperarse siguiéndose los rastros de los maestros más representativos, en la prolongación indiscutible que, en algunos autores españoles, ofrecen sus estilos y sus elecciones teórico-metodológicas, sus modos personales del quehacer académico también ${ }^{20}$.

Por otra parte, en contrapeso al interno aislacionismo voluntario en que a veces se desenvuelve nuestra producción, apuntan en cierto modo indicado-

20 La impronta del oficio se percibe más clara, muchas veces, entre quienes han ampliado su formación en el extranjero. Entre ellos, Moradiellos, E., para la historia de la política exterior, especialmente en (1996): La perfidia de Albión. El gobierno británico y la guerra civil española, Madrid, Siglo XXI,

Cuáles son los fundamentos normativos y las pautas comunes en España en este típo de discurso histórico en expansión (politica exterior/ relaciones internacionales), en PERElRA, J. C., (1992): «De la Historia Diplomática a la Historia de las Relaciones Internacionales: algo más que el cambio de un término»: Historia Contemporánea 7:155-182, y QuiNTANA F., (1996): «La historia de las relaciones internacionales en España: apuntes para un balance historiográfico», en CER1, La Historia de las Relaciones Internacionales: una visión desde España, Madrid, Dirección General de investigación Cientifica y Técnica del Ministerio de Educación y Ciencia: 9-65.

Alguna información en torno al hispanismo, que por sí solo exige ya ur análisis de alcance superior, puede obtenerse en los siguientes títulos (por fuerza desiguales entre si): AUBERT, P., y DEsvols, J. M., (1985): «Les Colloques de Pau et l'hispanisme français», Matériaux pour l'histoire du Xx siècle. (Cahiers de la Bibliothèque de Doc. Intern. Contemp., 3/4) Paris- $X$ Nanterre: 19-24; MATEOS, A., (1992): «Historiografia y visión de la España del siglo $\mathrm{xx}$ : los hispanistas anglosajones del 91»: Ayer 6: 139-146 y BoTTl, A., (1991): «Guerra y revolución en España en la historiografía del postfranquismon: Cuadernos Republicanos 8: 51-64.

Hispania, LVIIl/1, núm, 198 (1998) 65-95 
res varios de que sea posible todavía cierta reparación, en orden a la consecución de acuerdos y al fomento de discusiones entre cultivadores de campos diferentes. Quizá pueda traerse como fluctuante ejemplo, de evolución incierta, la evaluación en curso de la historia colonial española del siglo xix, ámbito de confluencia extensa para maneras muy distintas de abordar la historia, desde la política del estado central hasta las diversas fórmulas posibles de la historia local y regional ${ }^{21}$, y que ha recibido impulsos exteriores muy distintos, mirando hacia atrás, desde el 98 hasta el 92.

6. Mas conviene volver una vez más, aunque haya de resultar reiterativo, a destacar la pluralidad de influencias teóricas, la variedad de objetos diferentes y la mezcla de inspiraciones metodológicas que pueblan, desde hace por lo menos una década, el panorama de la historia contemporánea que viene haciéndose en España. Y que versa sobre España y su entidad histórica, muy especialmente, sólo asomada en los últimos tiempos nuestra historiografía hacia una historia supranacional.

La organización espacial de aquellas influencias, por distintas que sean y por contrapuestas (pues sigue sin haber una "escuela española de historiografía”, y seguramente es ya imposible que la haya, por diversas razones, me parece a mí), sigue en su clasificación cauces foráneos y rutas específicas de importación (utilizando el término en toda la extensión de la palabra).

Importación no ya sólo de autores propios del campo convencional de la historiografía (neomarxistas ingleses entre los más influyentes en su día, algún francés renovador de la historia política, casos aislados de la historia oral, entre los más frecuentes), sino también intportación de inspiraciones procedentes de espacios académicos distintos al de la historiografía, y derivadas de disciplinas colindantes. Y siendo todo ello manifiesto, por lo general, a través de los usos diversos y las adaptaciones que, de estos otros territorios multiparadigmáticos, han ido por su parte elaborando aquellos historiadores extranjeros que van sirviendo, a nuestra propia comunidad historiográfica, de modelo específico o de inspiración formal.

De unos y de otros va a tomarse, sin sistema completo y con cierto carácter aleatorio -encima dependiente, en gran medida a veces, de las traducciones-, alguna cosa sugerente o algún principio fundamental. La discusión del método se ceñirá ya así a la concreta aplicación de unos supuestos teóricos ya cristalizados. La búsqueda homogénea del objeto científico -ya sea clase social, cultura propia o rastreo biográfico y experiencial- se operará más de una vez por mímesis. Visible tentación que, sobre todo, aparece en los rótulos

21 Balances en OPATRNY, J., (1995): «Algunos apuntes sobre los estudios de historia de Cuba en Europa en los años 90", en Opatrny, J., ed. Cuba. Algunos problemas de su historia (Iberoamericana Pragensia. Supplementun 7/1995), Praga, Universidad Carolina: 5-18, o en mi prólogo (Espaítoles en Cuba; inás allá y más acá del 98: 7-23) a BLANCo, J. A., y ALonso, C., (1996); Presencia castellana en el Ejército Libertador cubano (1895-1898), Salamanca, Junta de Castilła y León. Una muestra plural de la historiografia más reciente en Narano, C., PUtG-SAMPER, M. A., y GarCia MORA, L. M., eds. (1996): La Nación Soñada: Cuba, Puerto Rico y Filipinas ante el 98, Aranjucz, Doce Calles. 
y en las etiquetas de las publicaciones aunque, quizá, no siempre reparando en sus obligaciones más comprometidas y en su retos implícitos. Sobre todo, gustan de utilizarse -antes de someterlas a un contraste empírico, pudiera ser, incluso- las etiquetas de experimentación, justo sólo los títulos de identificación de una tendencia nueva. Quizá sea ésta aún, más que ninguna otra, y en términos masivos, la senda utilizada en historiografía por la "novedad».

Soy consciente de que podrían hacérseme. llegados a este punto, desde la optica particular y la experiencia de quienes más cuidadosamente cultivan los campos mismos de la innovación, objeciones diversas y matizaciones sin género de dudas importantes. No estoy hablando de las excepciones, sin embargo, o de las trayectorias de excelencia, sino del estado general de la cuestion. Y es posible que algo más de lo hasta ahora visto pudiera avizorarse, por poner un ejemplo de los más invocados en los últimos años, en el caso de iniciarse un debate profundo sobre la «microhistoria», por ejemplo.

Sólo un acercamiento desde una perspectiva sinceramente crítica facilitará - eso creo yo al menos- la clarificación que parece precisa a estas alturas en nuestro trabajo, ayudándonos a comprender quizá los modos y maneras de resolver problemas específicos de nuestra profesión. Una tarea, sin duda, hecha y fraguada en luchas que son viejas, aunque las olvidemos periódicamente para seguir bregando con la "novedad" y con la «tradición", en deuda sempiterna con el tienzpo, y con el propio tiempo que nos resulta dado. Y, más concretamente, sólo una acercamiento desde esa perspectiva allanará los usos adecuados de los factores específicos de conceptualización ${ }^{22}$.

22 Hay sin embargo ejemplos muy diversos, que arrancan desde antiguo, a propósito de cómo entre otras varias posibilidades existentes - se afrontaban los retos de este constante encuentro, de esta discusión. Cito, entre otros posibles, a OrTi, A., (1975): "Estudio introductorio» a Joaquín Costa "1902": Oligarquia y caciquismo cono la forma de gobiemo en España. Urgencia y modo de cambiaria, Madrid, Ediciones de la Revista de Trabajo, vol.1; ALVAREZ JUNCO, J., (1985): «A vueltas con la revolución burguesan: Zona Abierta 36/37: 81-106; Alvarez Junco, J., y Pérez Ledesma, M., (1983): «Historia del movimiento obrero, iuna segunda ruptura?»: Revista de Occidente 12: 19-41; ARósTEGut, J., (1988): «Historia general e historia económica. Propuestas interdisciplinares», en GaRCia DeLgado, J. L., ed. La II República española. Bienio rectificador y frente popular, Madrid, Siglo XXI:261-271; PÉrez Ledesma, M., (1993): «"Cuando lleguen los días de la cólera" (Movimientos sociales, teoría e historia)", en SÁnCHEZ NisTAL, J. M., y otros, Problemas actuales de la Historia. III Jornadas de Estidios Históricos, Salamanca: 141-187; CARASA, P., ed. (1994): Elites. Prosopografia contemporánea, Valladolid, Universidad de Valladolid. O bien, como indicio quizá de nuevas convergencias entre historia del derecho e historia general, a CLAVERO, B., (1995): "Tẹiido de sueños. La historiografia juridica española y el problema del Estado»: Historia contemporánea 12: 25-48. Por último, como una muestra de las brechas abiertas por el hispantsmo francés, véase MAURICE, J., (1989): «Propuestas para una historia de la sociabilidad en la España contemporánean: Estudios de Historia Social 50/51: 133-143.

Párrafo aparte merece la consideración de la sociologia histórica. Sólo citaré ahora, para abreviar, a CASANOva, J., (1987): «Revoluciones sin revolucionarios: Theda Skocpol y su análisis histórico comparativo»: Zona Abierta 41/42: 81-102 y (1997): «La sociologia histórica en Españan: Historia, Antropología y Fuentes Orales 16: 61-74, así como a dos introductores del enfoque de Tilly, con aplicaciones especificas al caso español: Martinez Dorado, G., (1993): «La formación del Estado y la acción colectiva en España, 1808-1845w: Historia Social 15: 101-116 y CrUz, R., (1993): "Crisis del Estado y acción colectiva en el periodo de entreguerras 1917-1939», ibidem: 119-136.

Hixpeniu, LVISI/I, núın. 198 (1998) 65-95 
Con una perspectiva de ese alcance, es más, creo perfectamente posible el aceptar con sobriedad y fruto, por traer otro ejemplo, desafíos como el que partió en su día de la sociología histórica, un reto anglosajón a la historia social, importado hasta nuestros pupitres a finales de los años 80 (un reto estrella, hace sólo unos años, y ahora algo aletargado, si es cierta mi impresión). Y lo mismo me aventuro a decir, insistiendo si cabe, a propósito de la noción de "género". Categoría de análisis que ya no es, tan solo, un instrumento y un proceder complejo que se hacen emergentes en la historiografía, sino seguramente un territorio afianzado entre nosotros y en muy franca expansión.

La "historia oral", por poner el ejemplo más denso y más jugoso, va siendo receptiva, perceptiblemente, a corrientes diversas de la antropología (y lo va siendo afortunadamente, a mi modo de ver), lo mismo que a una cierta sociología cualitativa, enormemente interesante en sus usos también. La misma "historia de las relaciones de género" que acabo de citar, o la «historia de la vida cotidiana” ${ }^{23}$, encierran invariablemente, no me cabe la duda en torno a ello, un potencial inmenso de desarrollo empírico y de sofisticada reflexión. (Potencial que, conviene no olvidarlo, para rendir sus frutos, exige a los historiadores situarse siempre, como elemento básico de su común estilo intelectual y como punto de ruptura operativa, en ámbitos de cruce muy diversos, siempre en un territorio transdisciplinar).

Comienza a percibirse, cada vez más decidido y claro, a resultas de todo lo anterior y como indicio o exponente de esa situación, por frágiles e inconsistentes que parezcan sus brotes todavía, un nuevo resurgir de lo que hemos llamado hasta ahora mismo "historia cultural». Concepto éste ambiguo y polisémico,

${ }^{23}$ Para historia oral, por ejemplo BORDERIAS, C., (1993): "Cuatro generaciones de mujeres emigrantes: transmisión y cambio social", en Trujllano SANCHEZ, J. M., ed. Jornadas "Historia y Fuentes orales *. Mentoria y Sociedad en la España Contemporánea, Avila: 27-37 y (1995); «La historia oral en España a mediados de los noventas: Historia y Fuente oral 13: 113-130. También, VILANOVA, M., (1995): "El combate, en Espana, por una historia sin adjetivos con tuentes orales": Historia y Fuente Oral 14:95-116. Sobre las relaciones de género, convienen los balances de NASH, M., (1991): "Dos décadas de historia de las mujeres en España: una reconsideración»: Historia Social 9: 137-161 y (1995): "Identidades, representación cultural y discurso de género en la España contemporáneas, en CHALMETA, P., y otros, Cultura y culuras en la Historia, Salamanca, Universidad de Salamanca: 191-203. También Nielfa, G., coord. (1991): "Apéndice sobre el caso español» en Anderson, B. S., y Zinser, J. P., Historia de las mujeres: una historia propia, Barcelona, Crítica, vol.II.

Sobre la historia de la vida cotidiana, 1. MoLL, ed. (1985): La vida quotidiana dins la perspectiva històrica, Paima de Malforca, Institut d'Estudis Balèarics y, en ese mismo texto, TERRADAs, I.: «La història de les estructures i la història de la vida. Reflexions sobre les formes de relacionar la història local i la història general». Considero plenamente acertadas las consideraciones criticas de Isabel Moll en su texto «Una cuestión de perspectiva: la tensión entre micro-historia general y la historia de las elites» (en Carasa, P., ed. Elites. Prosopografía contemporánea, Valladolid, 1994: 63-71). Un tanto reductoras me parecen en cambio, a pesar de su fuerza persuasiva y su agudeza, las críticas de UCELAY DA CAL, E., (1990): «El concepte de "vida quotidiana" i l'estudi de la guerra civil», Acàcia l: 51-74.

Hisparia, LVIII/1, núm. 198 (1998) 65-95 
cuando no francamente heteróclito, y hasta divergente. $Y$ con aspiraciones indisimuladas - procedentes no tanto de la antropología, aunque puede que de ahí se deriven también algunas de sus incitaciones- a encabezar y controlar un nuevo intento de unificación historiográfica, un esfuerzo orientado a emprender un ultimísimo ejercicio cohesivo, con vistas a lograr restablecer la perdida homogeneidad disciplinar ${ }^{24}$. Se cruza esta tendencia sin embargo con otra dimensión ya antigua en la historiografía, multiplicando a consecuencia de ese cruce, haciéndolos estallar en diversas direcciones, los objetos de análisis y los temas de estudio. Y dando así lugar a interpretaciones muy diversas, centradas sobre situaciones específicas más que sobre proyectos homogéneos de sintetización. Se trata, en fin, de una tendencia de cierta tradición en la historiografía espanola: la de la "regionalización" del estudio de la historia ${ }^{25}$, la presencia constante de enfoques específicos, ya sean de ámbito político, social o cultural, estudios restringidos a los distintos espacios regionales y nacionalidades, cerrados sobre ellos en giro circular.

${ }^{24}$ Traté ya hace un tiempo de avizorar un cierto panorama sobre la historia cultural española en la pasada década en HERNÁNDEZ SANDOICA, E., (1987): "La sustracción del objeto. (Sobre historia de la cultura e historiadores en España, 1968/ 1986), en VV. AA. Problèmaticas em Historia Cultural, Oporto, Faculdade de Linguas e Literatura: 143-164. Más recientemente, Ruzz-MANJóN, O., (1996): «Nuevas orientaciones en historia cultural», en MORALEs, A., y EsTEBAN, M., eds, La Historia Conteniporánea en España. Primer Congreso de Historia Contemporánea de España, Salamanca: 197-205.

Muchos más indicadores pueden citarse aquí. Entre ellos algunos textos histórico-historiográficos de indudable interés (OLÁABRrI, I., (1995): «New» New History: A Longue Durée Structure»: History and Theory. Studies in the Philosophy of History, Middletown, Wesleyan University, 34/I: [-29) y una parte de los últimos esfuerzos colectivos por propiciar la discusión metodológica y teórica: ANDRÉS GALlEGo, J., dir. (1993): New History/Nouvelle Histoire. Hacia una Nueva Historia, Madrid, Actas, 1993 o OLÁBARRI, I., y CASPISTEGUI, F. J., dirs. (1996): La «nueva» historia cultiral: la influencia del postestructuralismo y el auge de la interdisciplinariedad, Madrid, Editorial Complutense, 1996. La misma impronta, sin embargo, en textos a su vez muy variados: WICKHAM, C., Kamen, H., Hernández Sandoica, E., (1995): Las crisis en la Historia. Vl Jornadas de Estudios Históricos, Salamanca, Universidad de Salamanca.

Representativos de los distintos modos y propuestas de aproximarse a la historia cultural son autores tan diversos como CACHO, V., (1995): «La imagen de la España finisecular», en VV. AA. Homenaje a Antonio de Bethencourt Massieu, Las Palmas de Gran Canaria, Ediciones del Cabildo Insular: 361-386; (1997): Repensar el 98, Madrid, Biblioteca Nueva, y CANAL, J., (1992): «La sociabilidad en los estudios sobre la Espan̂a contemporánea»: Historia Contemporánea 7: 183-208; (1993): «El concepto de sociabilidad en la historiografia contemporánea (Francia, Italia y España)». Siglo XxX. Revista de Historia 13, México: 5-25; (1993): «El carlisme. Notes per a una anàlisi de la producció historiogràfica del darrer quart del segle (1967-1992)», en CANAL, J., coord. El carlisme. Six estudis fonamentals, Barcelona, L'Avenç: 5-49.

25 Jover la destacaba ya en su texto (1960) «Panorama of Current...», 1032 ss., refiriéndose también a otros periodos de la historia de España, y no sólo a la historia contemporánea en particular. Consideraciones teórico-metodológicas interesantes, a propósito de «historia regional», se obtendrán a partir de autores españoles, tan distintos en su presupuestos, como Carreras y Olábarri. También, en diversas discusiones colectivas - -en castellano o en catalán-- sobre «historia local». Aunque conviene recordar que no son conceptos equivalentes ambos (aunque tengan inevitable relación), como tampoco la «historia local» es, forzosamente, «microhistoria».

Hixprisia, LVIII/I, núm. 198 (1998) 65-95 
Un hecho a destacar ahora, sin embargo, es que no estorba el crecimiento de esa tendencia regionalizadora de la historiografía, por lo que se ve, a la reciente atención brindada a la cuestión del Estado español, con sus límites, sus peculiaridades y su naturaleza interactiva con los nacionalismos periféricos. Convertido en objeto de discusión historiográfica y politológica reactualizado, se trata de un tema en pleno auge, en el que las historiografías nacionalistas florecidas en el marco del Estado autonómico no constituyen, por sí solas, el contexto de su limitación. De aquellas ha derivado, por su parte, la esperable atención a los nacionalismos periféricos, objeto ( $\mathrm{y}$ sujeto a la vez) de un interés cada día creciente y que trasciende lo particular ${ }^{26}$.

7. Procede ir estableciendo ahora, por nuestra parte, conclusiones. Siquiera sean éstas más provisionales de lo deseable y ajustadas al concreto marco de esta misma ocasión. Diré, ante todo, que el que fuera objetivo inicial de unas páginas como éstas (rastrear cuál haya sido la recepción de ciertas corrientes últimas de la historiografía occidental por parte de los contemporaneístas españoles), no ha quedado cumplido. Serán precisas,

26 Por diversas razones, variopintas, se recomienda la lectura de los siguientes textos: DF RIQUER, B. (1990): «Sobre el lugar de los nacionalismos-regionalismos en la Historia Contemporánea Española»: Historia Social 7: 105-126; FusI J. P., (1990); «Revisionismo critico e historia nacionalista. (A propósito de un artículo de Borja de Riquer)», ibidem: 127-134; LiNZ, J. J., (1992): «Los nacionalismos en España. Una perspectiva comparadas: Historia y Fuente Oral 7: 127-136; AGlRREAZKUENAGA, J. (1992): «La tradición historiográfica vasca: su desarrollo en el marco de las ciencias sociales»: Historia Contemporánea 7: 257-281; BerAMENDI, J. G., (1992): «La historiografia de los nacionalismos en Españan: Historia contemporánea 7: 135-154; NÚNEZ SEIXAS, X. M., (1992): «El mito del nacionalismo irlandés y su influencia en los nacionalismos gallego, vaseo y catalán (1880-1936)": Spagna Contemporanea 2, Turin: 25-58; ANGUERA, P., (1992): «L'endocentrisme en la historiografia de Catalunya: un fals nacionalisme»: Afers 13; GRANJA, J. L., (1992): «EI nacionalismo vasco: de la literatura histórica a la historiografían: Historia contemporánea 7: 209236; MARTiNEz FIOL, D., (1993): «Conmemoracions, catalanisme i historiografia. Una combinació imperfecta»: L'Avens 175: 42-47; RIQUER, B. de, (1993): «Reflexions entorn de la dèbil nacionalització espanyola del segle XIX»: L'Avenç 170: 8-15, y (1994): «La débil nacionalización española del siglo xIX»: Historia Social 20: 97-114 y (1994): «Aproximación al nacionalismo espajol contemporáneon: Studia Storica. Historia Contemporánea XI1: 11-29; ElorZA, A., (1994): «El nacionalismo vasco: la invención de ła tradiciónł: Manuscrits 12: 183-192.

Volcados hacia afuera, algunos de estos otros han recibido mayor proyección exterior: Fusı, J. P., (1990): “Centre and Periphery 1900-1936: National Integration and Regional Nationalisms Reconsidered», en LANNON, F., \& PRESTON, P., eds. Élites and Power in Twentieth-Century Spain. Essays in Honour of Sir Raymond Carr, Oxford, Clarendon Press: 33-44; NúNEz SEIXAs, X. M.: (1992): Historical Research on Regionalisn and Peripheral Nationalisn in Spain: a Reappraisal, Florencia, Instituto Universitario y (1993): Historiographical Approaches to Nationalisms in Spain, Saärbrucken, Verlagbreitenbach Publishers; BeramendI, J. G., MȦız, R., y NúÑez SeIXAs, X. M., (1994): Nationalisms in Europe. Past and Present, 2 vols. Santiago de Compostela; PAYNE, S. G., (1991): «Nationalism, Regionalism and Micronationalism in Spain»: Jounal of Contemporary History 26/3-4: 479-491, o quizá incluso el texto en alemán de MEES, L., (1992): «Das baskische Labyrinth. Sozialgeschichtliche Implikationen, Kulturelles Umfeld und politische Artikulation des baskischen Nationalismus 1876-1937\%: Archiv für Sozialgeschichte 32, Bonn: 33-55.

Hispania, LVIII/1, núm, 198 (1998) 65.95 
pues, otras aportaciones más pacientes y más laboriosas, capaces de dar cuenta de los cauces precisos de los trayectos específicos disciplinares que son a estas alturas, como ya hemos dicho, francamente plurales y mixtilíneos.

Pero ninguna de esas lecturas, me atrevería a opinar, logrará conseguir clarificar las cosas si no se parte, al fin, del dominio general de las implicaciones filosóficas - teóricas también, en sentido formal- que todo cambio intelectual lleva como alimento. Implicaciones que los cambios recientes habidos en nuestra disciplina han contenido ya, sin duda alguna. Sin que quepa al respecto esgrimir ningún tipo de opción particular en la interpretación o de significado alternativo, aderezado al gusto de cada cual.

Como tenía muy posiblemente que resultar al fin, han ido levantándose entre nosotros suficiencias escépticas y suspicacias reticentes. Resulta sin embargo, estando así las cosas, que sólo desde un conocimiento general siquiera aproximado- de cuáles sean los fundamentos teóricos de los nuevos supuestos, se llegará a entender tanto la intencionalidad como el significado de las nuevas opciones que se están importando. Opciones que sin lugar a dudas son, vistas desde aquel ángulo, algo más que una «moda" (aunque también sean esto, necesariamente).

Mejorará sustancialmente la perspectiva de nuestro microcosmos enfocada desde una plataforma de este tipo, me parece a mí. Que nos permitiría reconsiderar ciertos balances y ciertas valoraciones quejumbrosas. Así, quizá aquella carencia de «originalidad " consustantiva a la historiografía española, como a veces se ha dicho, podría leerse bajo una nueva luz. A este respecto, convendría recordar también, aunque pueda quizá considerarse obvio, que la originalidad de las escuelas historiográficas «clásicas» (o a punto de llegar a serlo) viene dada por el cruce constante, interactivo y vario (en todas partes, en un país u otro), entre los fustes filosóficos del pensamiento vivo, dominante en los centros de producción científica y en la universidad, y los esfuerzos propedéuticos - a su vez gobernados por el mismo timón-que se hallan en la base de sedimentación de las nuevas disciplinas "sociales», y en los aciertos de sus respectivos campos epistemológicos.

Lo mismo da, al efecto, que se trate del acoplamiento del neokantismo de Renouvier y la sociología durkheimiana, unidos, con la materia empírica de la historiografía (que es lo que, en su sustrato, identifica a Annales), o que busquemos la incidencia de los pragmatistas norteamericanos en recientes supuestos individualizadores de transformación de la disciplina. O que -en fin- persigamos las impostaciones fenomenológicas que hacen de la Erfahrung (la experiencia vivida y su fluido constante, siempre cambiante y móvil), el eje del objeto historiográfico mismo, y a la vez su razón profundísima de ser.

Para nadie es un secreto a estas alturas cuán lejos se ha movido, casi forzosamente, la filosofía española de la segunda mitad del siglo xx de su horizonte universal. Ni tampoco puede resultar desconocido el mecánico proceso compartimentador de las ciencias humanas que ha supuesto, en resumen, que los ejemplos vivos de la doble tensión, siempre existente, entre filosofía e historia basculen —optando por la filosofía de la historia- hacia el primero de esos polos, o que sus practicantes se hayan convertido - casos excepciona-

Hippanitl, LVIII/I, núm. 198 (1998) 65-95 
les- en cultivadores, más o menos felices, de una "historia intelectual" particular.

Sin poder extendernos en lo que, a este respecto, cabría la tentación de tratar de intuir en cuanto a las posibles consecuencias, sobre el pasado inmediato y el presente, en una situación intelectual como la española que es todavía insatisfactoria, la verdadera penuria general no procede con todo, necesariamente, de la falta de voluntad o de altura teórica de los historiadores españoles (que también es un ingrediente desde luego, pero no llega con todo a ser excepcional). $\mathrm{Ni}$, tampoco quizá, de una carencia de "imaginación" que nos convertiría, sin lugar a dudas, en inferiores frente a otros colegas de otros países, de otras latitudes-. Sino que, seguramente, procede de una anomalía estructural y de muy largo alcance, una carencia sorprendente por su extensión y hondura, esa antigua mordaza de la libertad de pensamiento que hace del panorama filosófico español un desierto sombreado por unas cuantas, posiblemente frágiles, palmeras.

Lo que a mí me sorprende, quizá indebidamente, es que a estas alturas cuando se ha detectado al parecer de nuevo entre nosotros un interés mayor por la teoría y la metodología, según la mayoría del gremio reconoce-, siga eludiéndose en más de una ocasión el esfuerzo de ahondar en las raíces intelectuales de la transformación. Es tarea que exige armarse de paciencia $-\mathrm{y}$ de lecturas que acaso puedan parecer impertinentes-, pero es tarea sin dudarlo rentable para lograr el exacto gobierno por los historiadores de los conceptos, las técnicas y los métodos nuevos. Y que, si bien es cierto que no puede realizarse de golpe, de una vez por todas, ni mucho menos nos ofrece recetas para su circunstancial aplicación, permite sin embargo a los profesionales elegir situarse con criterio formado en distintos lugares: desde la aceptación de una teoría compartida - con los sociólogos, con los antropólogos, no sé si el psicoanálisis- hasta su severísima, y ojalá que ilustrada, refutación ${ }^{27}$.

27 Aunque posiblemente sea insuficiente todavía a modo de réplica argumentada, no quiero dejar de señalar aqui, por su valor inaugural, un esfuerzo como el de P. Ruiz ToRRes al discutir («Comentario», pág. 185) el texto del fílósofo Cuartango, R, G. (1995): «Habitar en lo propto como en tierra extrañam: Historia y Fuente Oral 14: 175-184.

Hispania, LVII/1, núm. 198 (1998) 65-95 